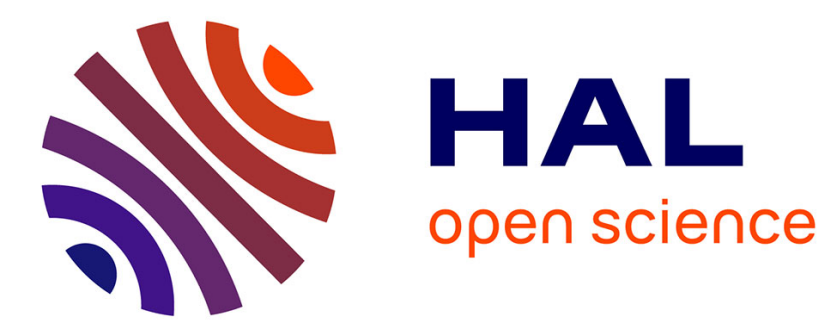

\title{
Isoselenocyanates versus Isothiocyanates and Isocyanates
}

Anna Chrostowska, Clovis Darrigan, Alain Dargelos, Alain Graciaa, Jean-Claude Guillemin

\section{To cite this version:}

Anna Chrostowska, Clovis Darrigan, Alain Dargelos, Alain Graciaa, Jean-Claude Guillemin. Isoselenocyanates versus Isothiocyanates and Isocyanates. Journal of Physical Chemistry A, 2018, 122 (11), pp.2894-2905. 10.1021/acs.jpca.7b12604 . hal-01744285

\section{HAL Id: hal-01744285 \\ https://hal-univ-rennes1.archives-ouvertes.fr/hal-01744285}

Submitted on 27 Apr 2018

HAL is a multi-disciplinary open access archive for the deposit and dissemination of scientific research documents, whether they are published or not. The documents may come from teaching and research institutions in France or abroad, or from public or private research centers.
L'archive ouverte pluridisciplinaire HAL, est destinée au dépôt et à la diffusion de documents scientifiques de niveau recherche, publiés ou non, émanant des établissements d'enseignement et de recherche français ou étrangers, des laboratoires publics ou privés. 


\title{
Isoselenocyanates versus Isothiocyanates and Isocyanates
}

\author{
Anna Chrostowska, ${ }^{\mathrm{a},}$ Clovis Darrigan, ${ }^{\mathrm{a}}$ Alain Dargelos, ${ }^{\mathrm{a}}$ Alain Graciaa, ${ }^{\mathrm{b}}$ Jean-Claude \\ Guillemin, ,,$*^{*}$ \\ ${ }^{a}$ Université de Pau et des Pays de l'Adour, CNRS, UMR 5254 IPREM, Institut des Sciences \\ Analytiques et de Physico-Chimie pour l'Environnement et les Matériaux, 64000 Pau, France \\ E-mail: anna.chrostowska@univ-pau.fr \\ ${ }^{\mathrm{b}}$ Université de Pau et des Pays de l'Adour, CNRS TOTAL-UMR 5150-LFC-R 64000 Pau, \\ France \\ ${ }^{\mathrm{c}}$ Univ Rennes, Ecole Nationale Supérieure de Chimie de Rennes, CNRS, ISCR - UMR6226, \\ F-35000 Rennes, France E-mail: jean-claude.guillemin@ensc-rennes.fr. tel. +33 (0)223238073
}

Dedicated to Professor Tamas Veszpremi for his $70^{\text {th }}$ birthday. 


\begin{abstract}
Alkyl and aryl isoselenocyanates are well-known intermediates in the synthesis of various organoselenium compounds but the knowledge of the physicochemical properties of simple unsaturated derivatives is still fragmentary. Vinyl-, 2-propenyl- and cyclopropyl isoselenocyanates have been prepared by reaction of selenium in powder with the corresponding isocyanides. The isoselenocyanates of this series, with a variable distance between the $\mathrm{N}=\mathrm{C}=\mathrm{Se}$ group and the unsaturated or pseudo-unsaturated group, have been studied by UV-photoelectron spectroscopy and quantum chemical calculations. For each of these three isoselenocyanates, the exploration of conformers and geometrical optimization always converge toward only one local minimum. The vinyl and cyclopropyl derivatives are characterized by similar order of magnitude of interactions between the NCSe group and the substituent, while for allylic compound two non-interacting moieties should be considered. The same conclusions were obtained for vinylic and cyclopropylic sulfur and oxygen derivatives.
\end{abstract}

Thus, the type and extent of interactions between the $\mathrm{N}=\mathrm{C}=\mathrm{X}(\mathrm{X}=\mathrm{O}, \mathrm{S}, \mathrm{Se})$ group and an unsaturated (vinyl, allyl or cyclopropyl) moiety are now clarified. 


\section{Introduction.}

Alkyl and aryl isoselenocyanates are very useful precursors or intermediates in the synthesis of biologically active organoselenium cyclic compounds or selenoureas. ${ }^{1-5}$ However, the synthesis and the physicochemical properties of simple unsaturated isoselenocyanates have been little studied compared to those of alkylated derivatives. The synthesis of the simplest organoselenocyanate, $\mathrm{CH}_{3}$-NCSe, was first reported in $1965,{ }^{6}$ but so far only a few functionalized derivatives have been synthesized. As an exception, the unsubstituted allyl derivative, $\mathrm{H}_{2} \mathrm{C}=\mathrm{CHCH}_{2} \mathrm{NCSe}$, has been characterized as early as $1963,{ }^{7}$ but in the presence of the allyl selenocyanate $\left(\mathrm{H}_{2} \mathrm{C}=\mathrm{CHCH}_{2} \mathrm{SeCN}\right)$ due to a [3,3]-sigmatropic rearrangement between both forms. In a study on such rearrangements with selenium derivatives, Banert and $\operatorname{Toth}^{8}$ reported a pioneering work on the formation of the simplest allenyl isoselenocyanate and substituted allenyl and vinyl derivatives. Recently the first preparation of the simplest vinyl isoselenocyanate $\left(\mathrm{H}_{2} \mathrm{C}=\mathrm{CHNCSe}\right)$ was reported and its microwave spectrum was recorded. ${ }^{9}$

The use of UV-photoelectron spectroscopy assisted by theoretical calculations in quite recent studies on unsaturated isocyanides, ${ }^{10}$ selenols, selenocyanides, ${ }^{11,12}$ and tellurols, ${ }^{13}$ has clarified the nature of the interactions between the heteroatomic group and the unsaturated substituent depending on the distance between the two functional groups. This approach was particularly well adapted to reveal similarities and differences in the orbitals more or less perturbed by the nature of interactions between groups. To the best of our knowledge, in the case of isoselenocyanates, only the photoelectron spectra of alkylated and silylated derivatives

have been reported. ${ }^{14-16}$ For $\alpha, \beta$ - or $\beta, \gamma$-unsaturated isoselenocyanates, interactions between NCSe and unsaturated groups can be identified and compared with those of a compound having a pseudo-unsaturated substituent such as cyclopropyl isoselenocyanate, with reported data on saturated isoselenocyanates and those of the isoelectronic oxygen or sulfur derivatives. We report here the photoelectron spectra of vinyl-, allyl- and cyclopropylisoselenocyanates 1-3 followed by the comparison of these spectra with those of the corresponding oxygen 4-6 and sulfur derivatives 7-9 analyzed for this study (Chart 1). The result of this study sheds some light to the understanding of the differences or similarities between unsaturated isocyanates, isothiocyanates and isoselenocyanates. 


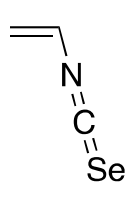

1

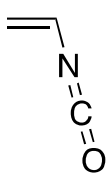

4

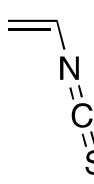

7

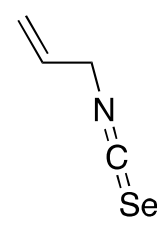

2

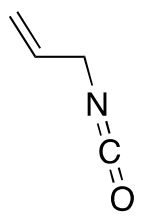

5

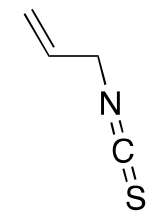

8

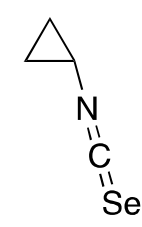

3

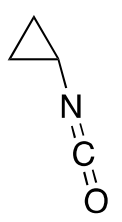

6

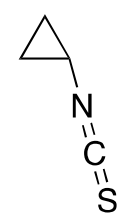

9

Chart 1. Vinyl-, allyl- and cyclopropyl-isoselenocyanates 1-3; vinyl-, allyl- and cyclopropylisocyanates 4-6; vinyl-, allyl- and cyclopropyl-isothiocyanates 7-9.

\section{Experimental Section}

Materials.

Allyl isocyanate $\mathbf{5}$ and allyl isothiocyanate $\mathbf{8}$ were purchased from the Aldrich Company. Vinyl isoselenocyanate $\mathbf{1}^{9}$, cyclopropyl isocyanate 4 and vinyl isothiocyanate $7^{17}$ have been synthesized as reported.

Caution: Isoselenocyanates are foul-smelling liquids and potentially toxic species that should be prepared under a well-ventilated hood.

Synthesis of allyl 2 and cyclopropyl isoselenocyanate 3. Into a one-necked cell equipped with a stopcock were introduced under nitrogen the isocyanide $(670 \mathrm{mg}, 10 \mathrm{mmol})$, chloroform (10 $\mathrm{mL}$ ), selenium powder (950 mg, $12 \mathrm{mmol})$, and few drops of tri-n-octylamine. The mixture was immersed in a liquid nitrogen bath and degassed. The stopcock was closed, and the mixture was heated at $50{ }^{\circ} \mathrm{C}(2)$ or $65{ }^{\circ} \mathrm{C}(3)$ overnight. The cell was then adapted to a vacuum line equipped with a U-tube with stopcocks and immersed in a bath cooled at $-45^{\circ} \mathrm{C}$. The solution was heated to $60{ }^{\circ} \mathrm{C}$ and distilled in vacuo $(0.1 \mathrm{mbar})$. The isoselenocyanate $\mathbf{2 , 3}$ 
was selectively trapped at $-45^{\circ} \mathrm{C}$. A second distillation can be performed to obtain a very pure sample.

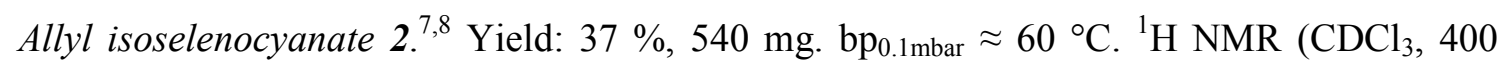
$\mathrm{MHz}) \delta 4.18\left(\mathrm{dt}, 1 \mathrm{H},{ }^{3} \mathrm{~J}_{\mathrm{HH}}=4.9 \mathrm{~Hz},{ }^{4} \mathrm{~J}_{\mathrm{HH}}=1.8 \mathrm{~Hz}, \mathrm{CH}_{2}-\mathrm{N}\right), 5.32\left(\mathrm{dt}, 1 \mathrm{H},{ }^{3} \mathrm{~J}_{\mathrm{HH} \text { trans }}=15.0 \mathrm{~Hz}\right.$, $\left.{ }^{4} \mathrm{~J}_{\mathrm{HH}}=1.8 \mathrm{~Hz}, \mathrm{HC} \underline{\mathrm{H}}=\mathrm{C}\right), 5.41\left(\mathrm{dt}, 1 \mathrm{H},{ }^{3} \mathrm{~J}_{\mathrm{HHcis}}=10.1 \mathrm{~Hz},{ }^{4} \mathrm{~J}_{\mathrm{HH}}=1.8 \mathrm{~Hz}, \underline{\mathrm{HCH}}=\mathrm{C}\right), 5.82$ (ddt, $\left.1 \mathrm{H},{ }^{3} \mathrm{~J}_{\mathrm{HHtrans}}=15.0 \mathrm{~Hz},{ }^{3} \mathrm{~J}_{\mathrm{HHcis}}=10.1 \mathrm{~Hz},{ }^{3} \mathrm{~J}_{\mathrm{HH}}=4.9 \mathrm{~Hz}, \mathrm{CH}\right) .{ }^{13} \mathrm{C} \mathrm{NMR}\left(\mathrm{CDCl}_{3}, 100 \mathrm{MHz}\right) \delta$ $47.5\left(\mathrm{t},{ }^{1} \mathrm{~J}_{\mathrm{CH}}=155.3 \mathrm{~Hz}, \mathrm{CH}_{2}\right), 118.5\left(\mathrm{t},{ }^{1} \mathrm{~J}_{\mathrm{CH}}=158.4 \mathrm{~Hz}, \underline{\mathrm{CH}}_{2}=\mathrm{C}\right), 124.8(\mathrm{~s}, \mathrm{NCSe}), 129.1(\mathrm{~d}$, $\left.{ }^{1} \mathrm{~J}_{\mathrm{CH}}=160.6 \mathrm{~Hz}, \mathrm{CH}_{2}=\underline{\mathrm{CH}}\right)$. A few percent of two minor impurities were observed in the PE and NMR spectra, the allyl selenocyanide coming from a [3,3]-sigmatropic rearrangement ${ }^{7,8}$ and the allyl isocyanide coming from the departure of the selenium atom.

Cyclopropyl isoselenocyanate 3. Yield: $47 \%, 686 \mathrm{mg}$. bp $0.1 \mathrm{mbar} \approx 60{ }^{\circ} \mathrm{C} .{ }^{1} \mathrm{H} \mathrm{NMR}\left(\mathrm{CDCl}_{3}\right.$, $400 \mathrm{MHz}) \delta 0.89\left(\mathrm{~m}, 2 \mathrm{H}, \mathrm{c}-\mathrm{CH}_{2}\right), 0.99\left(\mathrm{~m}, 2 \mathrm{H}, \mathrm{c}-\mathrm{CH}_{2}\right), 2.93\left(\mathrm{dddd}, 1 \mathrm{H},{ }^{3} \mathrm{~J}_{\mathrm{HH}}={ }^{3} \mathrm{~J}_{\mathrm{HH}}=7.3 \mathrm{~Hz}\right.$, $\left.{ }^{3} \mathrm{~J}_{\mathrm{HH}}={ }^{3} \mathrm{~J}_{\mathrm{HH}}=3.7 \mathrm{~Hz}, \mathrm{CH}\right) .{ }^{13} \mathrm{C} \mathrm{NMR}\left(\mathrm{CDCl}_{3}, 100 \mathrm{MHz}\right) \delta 8.46\left(\mathrm{t},{ }^{1} \mathrm{~J}_{\mathrm{CH}}=166.6 \mathrm{~Hz}, \mathrm{c}-\mathrm{CH}_{2}\right)$, 25.5 (d brd, ${ }^{1} \mathrm{~J}_{\mathrm{CH}}=190.7 \mathrm{~Hz}, \mathrm{CH}$ ), 118.4 (s brd, NCSe). HRMS calcd for $\mathrm{C}_{4} \mathrm{H}_{5} \mathrm{~N}^{80} \mathrm{Se}^{+}$: 146.9587. Found: 146.959. IR [ $v\left(\mathrm{~cm}^{-1}\right)$, gas phase] $3091\left(\mathrm{w}, v_{\mathrm{CH} 2}\right), 3010\left(\mathrm{~m}, v_{\mathrm{CH} 2}\right), 2924(\mathrm{~m})$, $2853(\mathrm{w}), 2142\left(\mathrm{~s}, v_{\mathrm{NCSe}}\right), 1349(\mathrm{~s}), 1031(\mathrm{~m}), 964(\mathrm{~m}), 812(\mathrm{~m})$.

\section{Computational Methods.}

All calculations were performed using the Gaussian $09^{18}$ software with the $6-311 \mathrm{G}(\mathrm{d}, \mathrm{p})$ basis set. DFT has been shown to predict various molecular properties of similar compounds successfully. ${ }^{19}$ All geometry optimizations were carried out with the range-separated hybrid CAM-B3LYP ${ }^{20-23}$ functional. Frequency calculations were performed in order to verify that the stationary points obtained were true energy minima. Possible conformers were investigated and optimized to find the most stable one. First vertical ionization energy $\left(I E_{1, v}\right)$ was calculated with $\triangle \mathrm{SCF}-\mathrm{DFT}$, as a difference between ground states of cation and neutral $\left(I E_{1, v}=E^{\text {cation }}-E^{\text {neutral }}\right)$ at the same geometry (of neutral system). ${ }^{24-26}$ The TDDFT ${ }^{27-30}$ approach was used for the calculation of higher ionization energies in combination with $\Delta$ SCF-DFT method. ${ }^{29,31,32}$ The vertical ionization energies were also calculated at the ab initio level according to $\mathrm{OVGF}^{33,34}$ and SAC-CI ${ }^{35-37}$ (Symmetry Adapted Cluster/Configuration Interaction) methods. We also use Koopmans' theorem ${ }^{38}$ for a rough estimation of IE, within frozen orbital approximation $\left(I E_{1}=-\varepsilon_{H O M O}^{K S}\right)$. Natural bonding analysis ${ }^{39,40}$ was performed with package included in Gaussian. Avogadro software ${ }^{41,42}$ has been used as a visualization tool for MOs. 


\section{Photoelectron Spectroscopy.}

The UV-PES spectra were recorded on a home-built (at the Institut of "Sciences Analytiques et de Physico-Chimie pour l'Environnement et les Matériaux" (IPREM)) three-part spectrometer equipped with a main body device, He-I radiation source $(21,21 \mathrm{eV}$ and/or $48 \mathrm{eV}$ ) and a $127^{\circ}$ cylindrical analyzer. The spectrometer works at constant analyzer energy under $5.10^{-6}$ Torr working pressure and $\leq 10^{-7}$ Torr for channeltron (X914L) pressure. The monitoring is done by a microcomputer supplemented by a digital-analogue converter (AEI spectrum). The spectra resulting from a single scan are built from 2048 points and are accurate within $0.05 \mathrm{eV}$. Spectra are calibrated with lines of xenon $(12.13$ and $13.44 \mathrm{eV})$ and of argon (15.76 and $15.94 \mathrm{eV})$. The accuracy of the ionization potentials is $+0.03 \mathrm{eV}$ for sharp peaks and $\pm 0.05 \mathrm{eV}$ for broad and overlapping signals.

Compounds 1-3 and 5-8 were slowly vaporized under low pressure (10 $0^{-6}$ Torr) inside handmade three valves injector (3/4 inch diameter; $10 \mathrm{~cm}$ length; working temperature: $190^{\circ} \mathrm{C} \leq \mathrm{T} \leq+300^{\circ} \mathrm{C}$ ) and the gaseous flow was then continuously and simultaneously analyzed by UV-photoelectron spectrometry.

\section{Results and Discussion}

\section{Calculated geometrical structures}

To the best of our knowledge, conformational analyses on allyl isoselenocyanate $\mathbf{2}$ or cyclopropyl isoselenocyanate $\mathbf{3}$ have not been investigated until now. In the allylic series, the presence of two conformers in the gas phase was predicted for allyl isocyanate $5^{43}$ and allyl isothiocyanate $\mathbf{8},{ }^{44}$ but only one conformer was characterized for each of them by microwave spectroscopy. ${ }^{45,46}$ Microwave spectra of both conformers were recorded for cyclopropyl isocyanate $6^{47,48}$ and cyclopropyl isothiocyanate $9,^{49,50}$ the antiperiplanar conformer being more abundant in both cases in the gas phase. For vinylic derivatives, theoretical calculations concluded that for any $\mathrm{H}_{2} \mathrm{C}=\mathrm{CHNCX}(\mathrm{X}=\mathrm{O}, \mathrm{S}$, or Se) both CCNC synperiplanar (sp) and antiperiplanar (ap) conformers should be present in the gas phase. ${ }^{51}$ However, even if both conformers were observed by microwave spectroscopy for $\mathrm{H}_{2} \mathrm{C}=\mathrm{CHNCO} 4$ with a major ap conformer, ${ }^{52}$ only the ap form was characterized for the sulfur ${ }^{53}$ and selenium derivative. ${ }^{9}$ In this recent study on vinyl isoselenocyanate $\mathbf{1}$, among the five different quantum chemical methodologies employed, namely MP2, CCSD(T), CCSD, B3LYP and M062X, only MP2 
predicted the existence of a synperiplanar form, which has not been found in the microwave spectra.

In order to elucidate the electronic structure differences of the three isoselenocyanates under study, CAM-B3LYP functional and 6-311G(d,p) basis set were applied to calculate geometrical structures of molecules 1-3. The selected geometrical parameters of most stable conformers (see Computational Methods for more details) of vinyl, allyl and cyclopropyl derivatives 1-9 are shown in Figure 1.
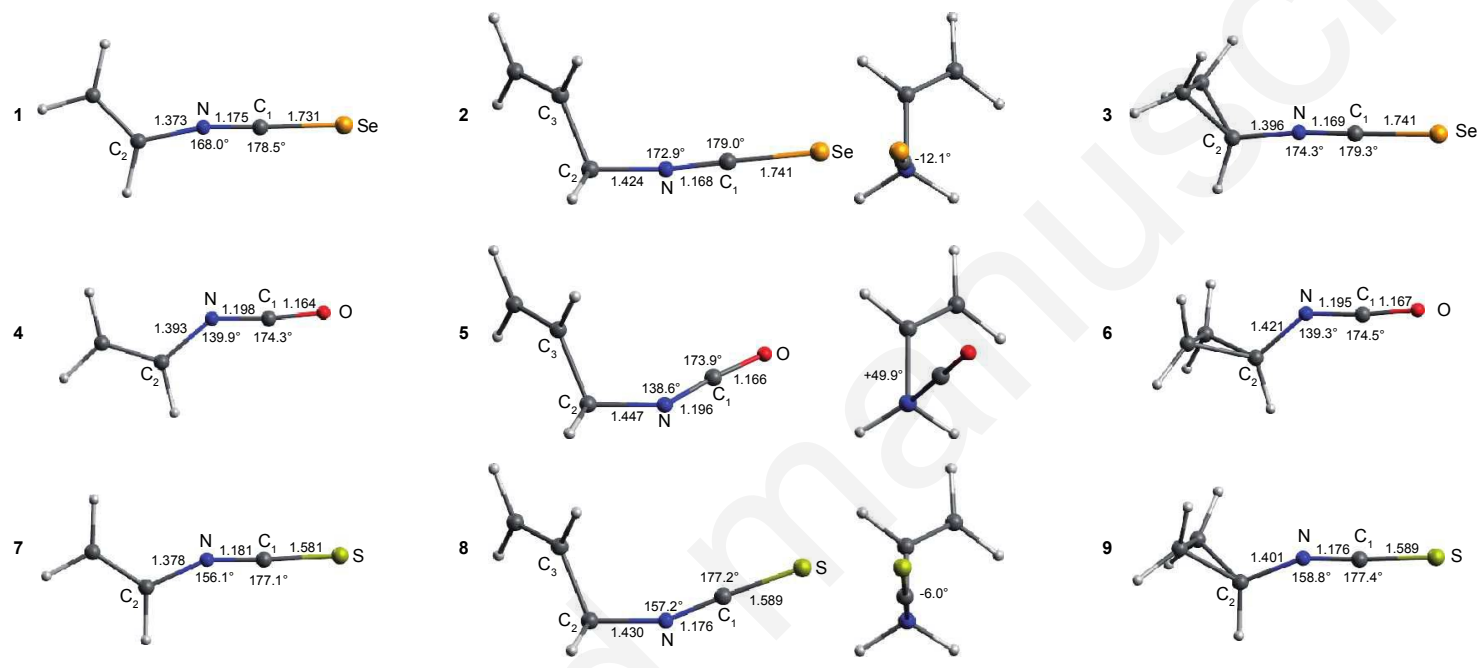

Figure 1. Selected geometrical parameters of: vinyl isoselenocyanate 1, allyl isoselenocyanate $\mathbf{2}$, cyclopropyl isoselenocyanate $\mathbf{3}$, vinyl isocyanate $\mathbf{4}$, allyl isocyanate $\mathbf{5}$, cyclopropyl isocyanate $\mathbf{6}$, vinyl isothiocyanate $\mathbf{7}$, allyl isothiocyanate $\mathbf{8}$ and cyclopropyl isothiocyanate 9. Bond lengths are in angstrom, angles in degree. For $\mathbf{2}, \mathbf{5}$ and $\mathbf{8}$, the views in alignment of $\mathrm{C}_{2}-\mathrm{N}$ bond allow to show the variation in dihedral angles $\mathrm{C}_{1}-\mathrm{N}-\mathrm{C}_{2}-\mathrm{C}_{3}$.

For each isoselenocyanate 1-3, the geometrical optimization and conformational analysis always converge toward a unique local minimum (Figure 1). For vinyl isocyanate 4 and cyclopropyl isocyanate 6, two conformers (local minima) were found, corresponding to antiperiplanar and synperiplanar forms $\left(\mathrm{C}_{\mathrm{s}}\right.$ symmetry). In both cases, the most stable conformer is ap, as shown in Figure 1 (see Supporting Information for details). The conformational analysis and geometrical optimization of allylisocyanate $\mathbf{5}$ and isothiocyanates 7-9 converge for each compound toward a unique local minimum as already observed for 
isoselenocyanates 1-3 (Figure 1). Despite that cyclopropyl isothiocyanate 9 has been described under different conformers, ${ }^{49}$ CAM-B3LYP functional only converges to ap geometry. Results with B3LYP are slightly different since we found both ap and sp forms, very close in energy (ap being the most stable). For $\mathrm{R}=$ vinyl, allyl or cyclopropyl in the RNCX series, we noted the same tendency of shortening $\mathrm{C}_{2}-\mathrm{N}$ and $\mathrm{N}-\mathrm{C}_{1}$ bonds, and enlargement of the bond angle $\mathrm{C}_{2} \mathrm{NC}_{1}$ in the order $\mathrm{O}, \mathrm{S}, \mathrm{Se}$. Nitrogen center changes from bent " $s p$ " hybridization in NCO to quasi-linear " $s p$ " hybridization in NCSe. For the RNCO series, the $\mathrm{C}_{2}-\mathrm{N}$ bond length is bigger when $\mathrm{C}_{2} \mathrm{NC}_{1}$ bond angle is smaller in order: 4, 6, 5. In all cases, NCX is not linear; the smallest values for NCX angle correspond to the NCO (5: $\left.173.9^{\circ} ; \mathbf{4}: 174.3^{\circ} ; \mathbf{6}: 174.5^{\circ}\right)$, but the nearly linear framework is calculated for NCSe group (1: $\left.178.5^{\circ} ; 2: 179.0^{\circ} ; 3: 179.3^{\circ}\right)$. The most remarkable parameter change is the dihedral angle variation between allyl and $\mathrm{NCX}$ groups $\left(\mathrm{C}_{1}-\mathrm{N}-\mathrm{C}_{2}-\mathrm{C}_{3}\right.$ torsion angle): very different from a synperiplanar conformation for $\mathrm{NCO}$ group $\left(+49.9^{\circ}\right)$, but close to a synperiplanar conformation for NCS and NCSe groups $\left(-6^{\circ}\right.$ and $-12.1^{\circ}$, respectively. The bond length between $\mathrm{C}_{1}$ and heteroatom $\mathrm{X}$ is increasing, with respect to atomic radius of $\mathrm{X}$.

The Natural Bonding Orbital (NBO) analysis of these compounds (Figure 2) gives more precise information related to geometrical description. In the case of NCSe and NCS groups, the $\mathrm{N}-\mathrm{C}_{1}$ bond looks like a triple bond (occupation close to 6 electrons), whereas $\mathrm{C}_{1}-\mathrm{S}$ and $\mathrm{C}_{1}$ Se bonds correspond clearly to a single bond (occupation close to 2 electrons). Nitrogen has no more its lone pair in these cases; these configurations correspond to $\mathrm{R}-\mathrm{N} \equiv \mathrm{C}-\mathrm{X}$ Lewis' structure. For the NCO group, NBO's occupations clearly indicate that $\mathrm{N}-\mathrm{C}_{1}$ bond should be considered as a double bond (occupation close to 4 electrons) as well as the $\mathrm{C}_{1}$-O bond, with a true lone pair localized on nitrogen. Such compounds correspond to $\mathrm{R}-\mathrm{N}=\mathrm{C}=\mathrm{O}$ Lewis' structure. These NBO results are consistent with previous geometrical description: for NCO series, $\mathrm{C}_{1} \mathrm{NC}_{2}$ bond angle increases while hybridization parameter $\lambda$ decreases (allyl: $138.6^{\circ} / \mathrm{sp}^{1.59}$; cyclopropyl: $139.3^{\circ} / \mathrm{sp}^{1.51}$; vinyl: $139.9^{\circ} / \mathrm{sp}^{1.42}$ ). For NCS and NCSe series, this trend cannot be confirmed, due to a very low variation of parameter $\lambda($ near $1.11 \pm 0.01$ ). 
4
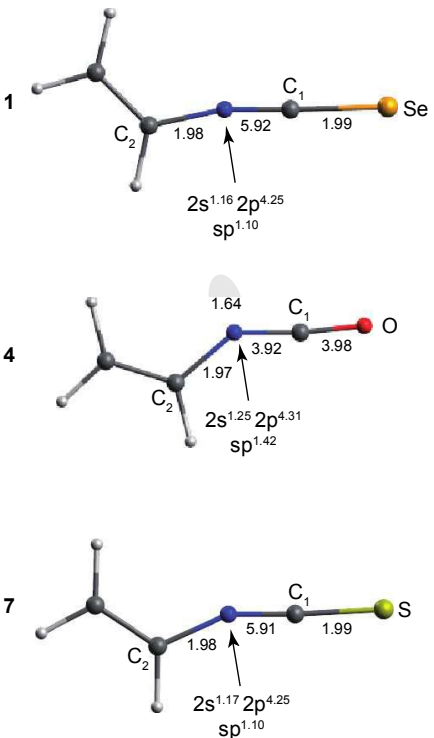
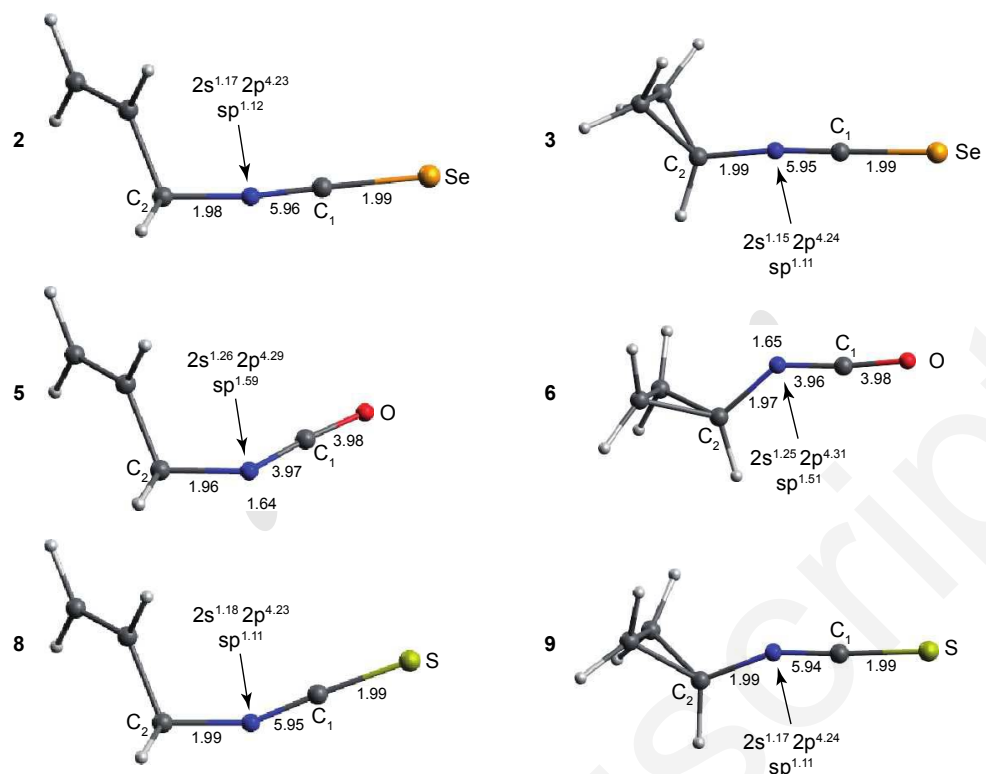

6
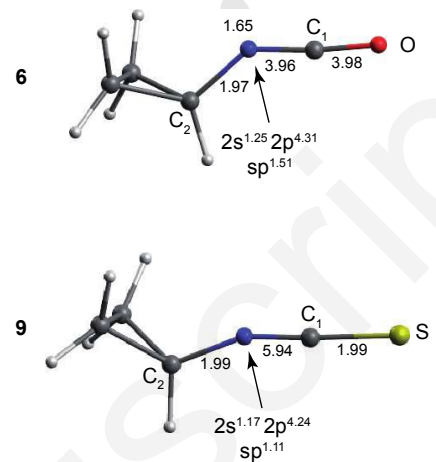

Figure 2. Natural Bonding Orbital (NBO) analysis of compounds 1-9. Numbers on bonds correspond to NBO's occupations (single bond close to 2; double bond close to 4; triple bond close to 6 ; lone pair of nitrogen represented in grey). Natural electron configuration $\left(2 \mathrm{~s}^{m} 2 \mathrm{p}^{n}\right)$ for nitrogen atom is given, and also $\mathrm{sp}^{\lambda}$ hybridization of nitrogen in $\mathrm{C}_{2}-\mathrm{N}$ bond.

\section{Synthesis of Isoselenocyanates 1-3.}

Vinyl 1, allyl $\mathbf{2}$ and cyclopropyl isoselenocyanate $\mathbf{3}$ have been synthesized by heating of a mixture of the corresponding isocyanide with selenium in the presence of a base, the tri-noctylamine, and with chloroform as solvent. Purification was performed on a vacuum line by selective trapping of the isoselenocyanates. Characterization was performed by ${ }^{1} \mathrm{H}$ and ${ }^{13} \mathrm{C}$ NMR spectroscopy and high-resolution mass spectrometry. In ${ }^{13} \mathrm{C}$ NMR spectroscopy, the broad signal around $\delta 125 \mathrm{ppm}$ is typical of the NCSe chemical shift.

\section{$U V$-photoelectron spectra assignments and theoretical evaluation of ionization energies}

The photoelectron spectra of the vinyl isocyanate $4^{52}$ and cyclopropyl isothiocyanate $9^{54}$ have already been recorded and analyzed. However, for sake of consistency and to allow a direct comparison between the compounds under current investigation, we also calculated the IEs of previously published UV-PES results of compounds $4{ }^{52}$ and $9 .^{54}$ For the reliable 
assignment of PE bands, density functional theory [ $\triangle \mathrm{SCF}+\mathrm{TD}-\mathrm{DFT}$ (CAM-B3LYP)] and $a b$ initio (OVGF and SAC-CI) calculations of ionization energies using the 6-311G(d,p) basis set have been carried out on optimized geometrical structures of 1-9. The comparison of the theoretically predicted IEs and experimental data are summarized in Tables 1-3 and S1-S6 in the Supp. Inf. section.

The recorded UV-photoelectron spectra of vinyl isoselenocyanate $\mathbf{1}$ and vinyl isothiocyanate 7 are depicted in Figure 3. The PE spectrum of isoselenocyanate 1 shows two first IEs at 8.9 $\mathrm{eV}$ and $10.8 \mathrm{eV}$, which are followed by a group of three broad bands at 12.8, 13.9 and 14.65 $\mathrm{eV}$. The first intense PE band of isothiocyanate 7 is located at $9.1 \mathrm{eV}$ and is well separated from the less intense, right side shoulder at $9.6 \mathrm{eV}$. The sharp band at $11.1 \mathrm{eV}$ is followed by higher-energy ionizations at 12.9 and $13.85 \mathrm{eV}$.
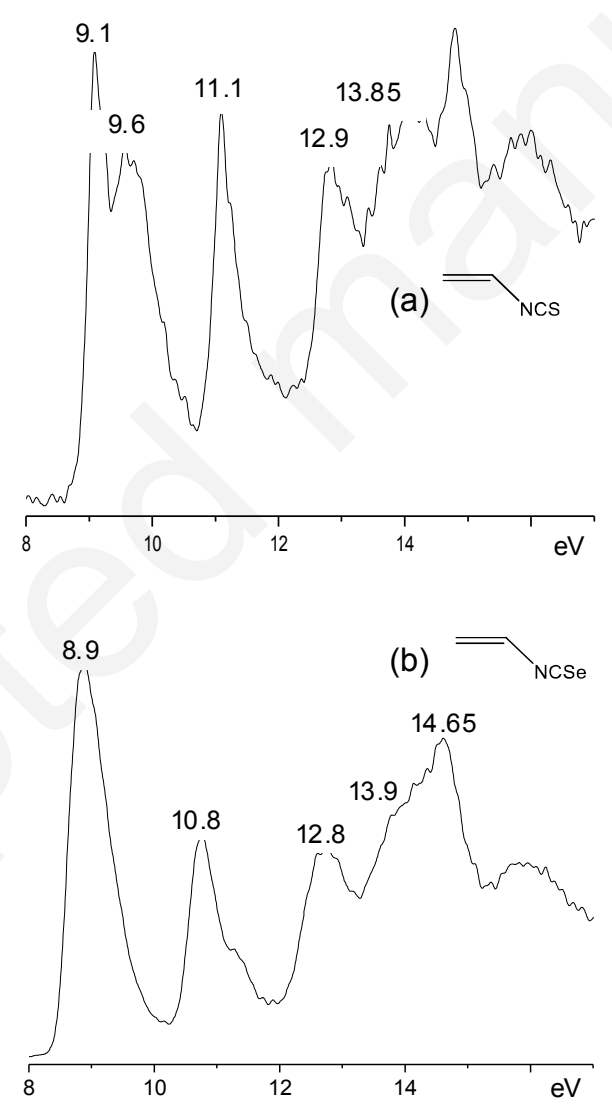

Figure 3. UV-Photoelectron spectra of (a) vinyl isothiocyanate 7; (b) vinyl isoselenocyanate $\mathbf{1}$.

The assignment of these experimental results is corroborated by the theoretical evaluation of ionization energies and is summarized in Table 1 for vinyl isoselenocyanate $\mathbf{1}$, and in Table 3 for vinyl isothiocyanate 7, while Table 2 contains previously published UV- 
PES data of vinyl isocyanate $4 .^{52}$ Also, the comparison of all UV-PES data of studied compounds 1, 4, 7 with those of methyl isocyanate, isothiocyanate and isoselenocyanate, as well as of the parent acids HNCO and HNCS, is useful. After some debate, the assignment of UV-PES data of these compounds have been clarified using Penning ionization electron spectroscopy. ${ }^{55,56}$ The experimentally determined first IEs for $\mathrm{CH}_{3} \mathrm{NCX}$ series $(\mathrm{X}=\mathrm{O}: 10.67$ $\mathrm{eV} ; \mathrm{X}=\mathrm{S}: 9.35 \mathrm{eV} ; \mathrm{X}=\mathrm{Se}: 8.93 \mathrm{eV})^{14}$ show clearly the significant influence of the chalcogen atom on the energetic position of the corresponding HOMO. For these three alkyl derivatives, ${ }^{14}$ the first and second ionization energies correspond to the out-of-phase ( $\pi^{*}$ and $\pi$ $\left.{ }^{\perp *}\right)$ MOs of the $-\mathrm{NCX}(\mathrm{X}=\mathrm{O}, \mathrm{S}, \mathrm{Se})$ group. For the vinyl substituted RNCX series, the first IEs of 1,4 and 7 arise from the antibonding interaction between the $\pi^{*}{ }_{\mathrm{NCX}}$ and the $\pi_{\mathrm{C}=\mathrm{C}}$ MOs of vinyl substituent, while the third IEs are linked with the antibonding interaction between the $\pi_{\mathrm{NCX}}$ and the $\pi_{\mathrm{C}=\mathrm{C}}$ MOs. The contribution of the $\mathrm{p}$ orbital of sulfur and selenium, respectively, is quite important, and these interactions lower the first IE value in comparison with their oxygen analogue: $\mathrm{IE}=9.8 \mathrm{eV}$ for $4,^{52} 9.1 \mathrm{eV}$ for 7 and $8.9 \mathrm{eV}$ for $\mathbf{1}$. For the third IEs, this destabilizing effect is even more pronounced and follows to the lower IE values versus $\mathrm{CH}_{2}=\mathrm{CH}-\mathrm{NCO}(12.65 \mathrm{eV})$ by $1.55 \mathrm{eV}$ for $7(11.1 \mathrm{eV})$ and by $1.85 \mathrm{eV}$ for $\mathbf{1}(10.8 \mathrm{eV})$. It should be stressed that the nature of the first IE of 1, $\mathbf{4}$ and $\mathbf{7}$ is substantially the same, but in the case of the third IE, the bonding interaction between the vinyl group and the nitrogen lone pair is privileged in $\mathbf{4}$, while the bonding interaction between nitrogen lone pair and $\pi_{\mathrm{CSe}}$ is noted in $\mathbf{1}$.

The second IEs of $\mathbf{1}, \mathbf{4}$ and 7 are attributed to the $\pi^{\perp *}{ }_{\mathrm{NCX}}$ in interaction with the $\sigma_{\mathrm{CH}}$ (8.9 eV for $1 ; 11.28 \mathrm{eV}$ for $4 ; 9.6 \mathrm{eV}$ for 7 ), while the nature of the fourth, also of a' symmetry, corresponds to the $\pi^{\perp} \mathrm{NCX}$ in interaction with the $\sigma_{\mathrm{CH}}$ in the case of $1(12.8 \mathrm{eV})$ and $7(12.9 \mathrm{eV})$, but to the fifth IE for $4(14.97 \mathrm{eV})$; the fourth band of $4(14.03 \mathrm{eV})$ is attributed to the $\sigma_{\mathrm{CH}}^{-}$ionization.

The comparison of these data for the first four IE values is presented on Figure 4. 
Table 1. Comparison of calculated and experimental ionization energies $[\mathrm{eV}]$ of vinyl isoselenocyanate $\mathbf{1}$.

\begin{tabular}{|c|c|c|c|c|c|c|}
\hline MO's nature & 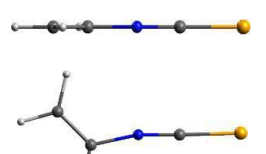 & $\begin{array}{c}\text { CAM-B3LYP } \\
-\varepsilon^{\mathrm{KS}}\end{array}$ & $\begin{array}{c}\text { CAM-B3LYP } \\
\Delta \text { SCF+TD- } \\
\text { DFT }\end{array}$ & OVGF & $\mathrm{SAC}-\mathrm{Cl}$ & Exp. \\
\hline $\begin{array}{c}\text { a" } \\
\pi_{\mathrm{NCSe}}^{*}-\pi_{\mathrm{CC}}\end{array}$ & & 7.751 & 8.621 & 8.329 & 8.825 & 8.9 \\
\hline $\begin{array}{c}\mathrm{a}^{\prime} \\
\pi^{\perp *}{ }_{\mathrm{NCSe}}\end{array}$ & & 8.010 & 8.920 & 8.497 & 8.522 & 8.9 \\
\hline $\begin{array}{c}\text { a" } \\
\pi_{\mathrm{CC}}-\pi_{\mathrm{NCS}}\end{array}$ & & 10.211 & 11.007 & 10.871 & 10.976 & 10.8 \\
\hline $\begin{array}{c}\mathrm{a}^{\prime} \\
\pi^{\perp} \mathrm{NCSe}-\sigma_{\mathrm{CH}}\end{array}$ & & 12.532 & 12.991 & 12.995 & 13.064 & 12.8 \\
\hline $\begin{array}{c}a^{\prime} \\
\sigma_{\mathrm{CH}} ; \mathrm{n}_{\mathrm{Se}}^{\sigma}\end{array}$ & & 13.243 & 13.356 & 13.914 & 14.074 & 13.9 \\
\hline $\begin{array}{c}\mathrm{a}^{\prime} \\
\mathrm{n}_{\mathrm{Se}}^{\sigma} ; \sigma_{\mathrm{CH}}\end{array}$ & & 13.611 & 13.967 & 14.606 & 14.668 & 14.65 \\
\hline
\end{tabular}


Table 2. Comparison of calculated and experimental ${ }^{52}$ ionization energies $[\mathrm{eV}]$ of vinyl isocyanate 4 .

\begin{tabular}{|c|c|c|c|c|c|c|}
\hline MO's nature & $\rightarrow$ & $\underset{-\varepsilon}{\text { CAM-B3LYP }}$ & $\begin{array}{l}\text { CAM-B3LYP } \\
\begin{array}{l}\Delta \text { SCF+TD- } \\
\text { DFT }\end{array}\end{array}$ & OVGF & SAC-CI & Exp. \\
\hline $\begin{array}{c}\mathrm{a"} \\
\pi_{\mathrm{NCO}}^{*}-\pi_{\mathrm{CC}}\end{array}$ & & 8.511 & 9.543 & 9.468 & 9.405 & 9.8 \\
\hline $\begin{array}{c}\mathrm{a}^{\prime} \\
\pi^{\perp *}{ }_{\mathrm{NCO}}\end{array}$ & & 10.199 & 11.277 & 10.992 & 11.087 & 11.28 \\
\hline $\begin{array}{c}\mathrm{a}^{\prime} \\
\pi_{\mathrm{CC}}+\pi^{*}{ }_{\mathrm{NCO}}\end{array}$ & & 11.699 & 12.816 & 12.563 & 12.640 & 12.65 \\
\hline $\begin{array}{c}a^{\prime} \\
\sigma_{\mathrm{CH}}\end{array}$ & & 12.868 & 13.866 & 14.186 & 14.150 & 14.03 \\
\hline $\begin{array}{c}\mathrm{a}^{\prime} \\
\pi^{\perp} \mathrm{NCO}-\sigma_{\mathrm{CH}}\end{array}$ & & 13.992 & 15.064 & 15.079 & 15.079 & 14.97 \\
\hline $\begin{array}{c}a^{\prime \prime} \\
\pi_{\mathrm{NCO}}\end{array}$ & & 15.023 & 15.708 & 15.897 & 15.854 & 15.43 \\
\hline
\end{tabular}


Table 3. Comparison of calculated and experimental ionization energies $[\mathrm{eV}]$ of vinyl isothiocyanate 7 .

\begin{tabular}{|c|c|c|c|c|c|c|}
\hline MO's nature & $\leftrightarrow \longrightarrow$ & $\begin{array}{c}\text { CAM-B3LYP } \\
-\varepsilon^{K S}\end{array}$ & $\begin{array}{c}\text { CAM-B3LYP } \\
\Delta \text { SCF+TD- } \\
\text { DFT }\end{array}$ & OVGF & SAC-CI & Exp. \\
\hline $\begin{array}{c}\text { a" } \\
\pi_{\mathrm{NCS}}^{*}-\pi_{\mathrm{CC}}\end{array}$ & & 8.113 & 8.961 & 8.594 & 8.667 & 9.1 \\
\hline $\begin{array}{c}a^{\prime} \\
\pi^{\perp *}{ }_{N C S}\end{array}$ & & 8.670 & 9.599 & 9.060 & 9.117 & 9.6 \\
\hline $\begin{array}{c}a^{\prime \prime} \\
\pi_{\mathrm{CC}}-\pi_{\mathrm{NCS}}\end{array}$ & & 10.440 & 11.343 & 11.032 & 11.127 & 11.1 \\
\hline $\begin{array}{c}\mathrm{a}^{\prime} \\
\pi^{\perp} \mathrm{NCS}-\sigma_{\mathrm{CH}}\end{array}$ & & 12.614 & 13.275 & 13.129 & 13.145 & 12.9 \\
\hline $\begin{array}{c}a^{\prime} \\
\sigma_{\mathrm{CH}}\end{array}$ & & 13.272 & 14.114 & 14.259 & 14.306 & 13.85 \\
\hline $\begin{array}{c}a^{\prime} \\
n_{S}^{\sigma} ; \sigma_{C H}\end{array}$ & & 13.970 & 15.038 & 14.666 & 14.815 & 14.1 \\
\hline
\end{tabular}




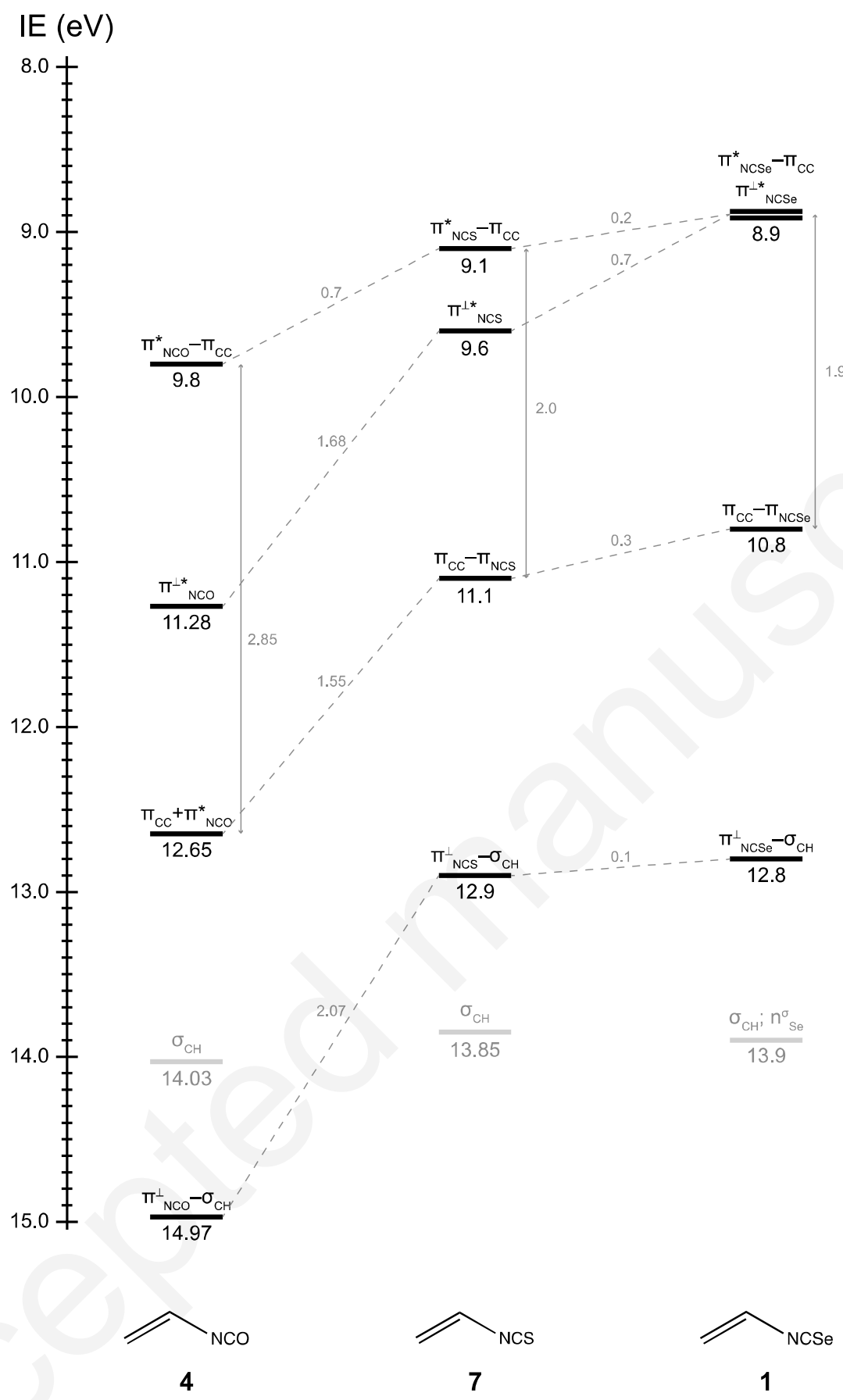

Figure 4. Comparison of the first four experimental ionization energies $[\mathrm{eV}]$ of vinyl isocyanate $4,{ }^{52}$ vinyl isothiocyanate 7 and vinyl isoselenocyanate $\mathbf{1}$.

The influence of the chalcogen atom in the series of vinyl isocyanates $-N=C=X(X=$ $\mathrm{O}, \mathrm{S}, \mathrm{Se}$ ) is clearly evidenced by the global lowering of all IEs with sulfur or selenium containing $-\mathrm{N}=\mathrm{C}=\mathrm{X}$ functional group in comparison with $-\mathrm{N}=\mathrm{C}=\mathrm{O}$. The HOMO energy increases (IE decreases) by $0.7 \mathrm{eV}$ for vinyl isothiocyanate and by $0.9 \mathrm{eV}$ for vinyl 
isoselenocyanate in comparison with the vinyl isocyanate, respectively. It should be noted that the next $\mathrm{MO}$ energies destabilizations are really significant if going from $\mathrm{X}=\mathrm{O}$ to $\mathrm{X}=\mathrm{S}$ or $\mathrm{X}$ $=\mathrm{Se}$, as for example for the $2^{\text {nd }}$ IEs: $1.68 \mathrm{eV}$ for $\mathrm{X}=\mathrm{O} \rightarrow \mathrm{X}=\mathrm{S}$ and $2.38 \mathrm{eV}$ for $\mathrm{X}=\mathrm{S} \rightarrow \mathrm{X}$ $=$ Se. The energy difference between the first and the third IEs corresponds to the strength of vinyl substituent $\left(\pi_{\mathrm{C}=\mathrm{C}}\right)$ interaction with $-\mathrm{N}=\mathrm{C}=\mathrm{X}$ group and is the biggest one for $\mathrm{CH}_{2}=\mathrm{CH}$ $\mathrm{NCO}(2.85 \mathrm{eV})$, while for $\mathrm{CH}_{2}=\mathrm{CH}-\mathrm{NCS}(2.0 \mathrm{eV})$ and $\mathrm{CH}_{2}=\mathrm{CH}-\mathrm{NCSe}(1.9 \mathrm{eV})$ this difference is significantly weaker.

It should be stressed that the theoretical evaluation of ionization energies (IEs) fits very nicely with the Time-Dependent Density Functional Theory (TD-DFT) method, combined with $\triangle \mathrm{SCF}$ approach $(\triangle \mathrm{SCF}+\mathrm{TD}-\mathrm{DFT})$, while outer valence green function (OVGF) and SAC-CI ab initio methods slightly underestimate two first IEs in the case of isoselenocyanate $\mathbf{1}$ and isothiocyanate 7, versus experimental data, respectively.

Figure 5 displays the UV-PE spectra of allyl isoselenocyanate 2, allyl isocyanate $\mathbf{5}$ and allyl isothiocyanate 8. The comparison of these experimental data with $\triangle \mathrm{SCF} / \mathrm{TD}-\mathrm{DFT}$, OVGF and SAC-CI calculated IEs is presented in Tables S1 (for 2), S3 (for 5) and S5 (for 8) in the Supporting Information. For the allyl isoselenocyanate 2 (the impurity at $8.2 \mathrm{eV}$ corresponds probably to $\mathrm{Se}_{2}$ or polymeric selenium ${ }^{57,58}$ ) and allyl isothiocyanate $\mathbf{8}$, the two first IEs (2: $8.75 \mathrm{eV})(\mathbf{8}: 9.25 \mathrm{eV})$ are due to the nearly isolated $-\mathrm{NCX}$ ionizations $\left(\pi_{\mathrm{NCX}}^{*}\right.$ and $\left.\pi^{\perp *}{ }_{\mathrm{NCX}}\right)$. The almost non-perturbed $\pi_{\mathrm{C}=\mathrm{C}}$ ionization appears as the second band in the case of 2 $(10.5 \mathrm{eV})$ and $\mathbf{8}(10.55 \mathrm{eV})$ and at the same value as for ethylene $(10.55 \mathrm{eV}) .^{59}$ The third, fourth and fifth bands of $\mathbf{2}$ and $\mathbf{8}$ are attributed to the $\pi^{\perp} \mathrm{NCX}-\sigma_{\mathrm{CH}}, \pi_{\mathrm{NCX}}-\sigma_{\mathrm{CH}}, \pi^{\perp}{ }_{\mathrm{NCX}}-\sigma_{\mathrm{CC}}$ MO's ionizations, respectively. The situation is quite different for allyl isocyanate 5: the first PE band (located at $10.25 \mathrm{eV}$ ) corresponds to the through-space antibonding interaction between the $\pi_{\mathrm{NCO}}^{*}$ and the $\pi_{\mathrm{C}=\mathrm{C}}$ MOs of allyl substituent, while the second IE is linked with the through-space antibonding interaction between the $\pi^{\perp *}$ NCO and the $\pi \ldots$ MOs $(510.7 \mathrm{eV})$. The third PE band of 5 is associated with the $\pi^{\perp *}$ NCO and the $\sigma \cdot \mathrm{H}$ MOs $(11.1 \mathrm{eV})$ and the fourth one $(13.0 \mathrm{eV})$ to the pseudo- $\pi$ of $\mathrm{CH}_{2}$. 

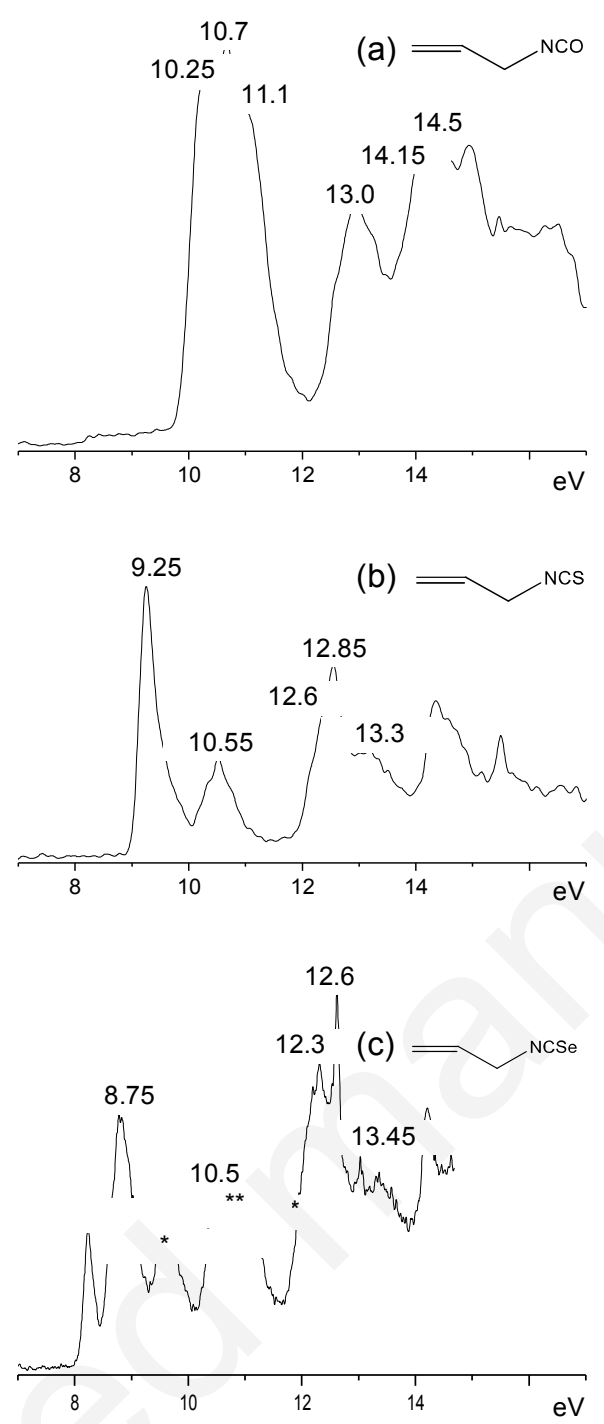

Figure 5. UV-Photoelectron spectra of (a) allyl isocyanate 5; (b) allyl isothiocyanate $\mathbf{8}$; (c) allyl isoselenocyanate $2, \diamond$ impurity, $*$ allylselenocyanate, $* *$ allylisocyanide (see Experimental Section).

The influence of the chalcogen atom in the allyl substituent series is illustrated by the comparison of the first four experimental ionization energies of allyl isocyanate 5, allyl isothiocyanate $\mathbf{8}$ and allyl isoselenocyanate $\mathbf{2}$ (Figure 6). As noted for vinyl derivatives, the replacement of the oxygen atom by sulfur causes a destabilization of HOMO $(1 \mathrm{eV})$, while for selenium this destabilization is more important $(1.5 \mathrm{eV})$. The same tendency, but of greater impact is observed with allyl derivatives for HOMO-1 $(\mathrm{X}=\mathrm{O} \rightarrow \mathrm{X}=\mathrm{S} 1.45 \mathrm{eV} ; \mathrm{X}=\mathrm{O} \rightarrow \mathrm{X}$ $=\mathrm{Se} 1.95 \mathrm{eV}$ ). The most important difference concerns the isocyanate unit interacting through space with allyl substituent, whereas it does not take place for isothiocyanate $\mathbf{8}$ and isoselenocyanate 2. Keeping with this, we can consider rather two isolated moieties in the case of the $\mathrm{H}_{2} \mathrm{C}=\mathrm{CH}-\mathrm{CH}_{2}-\mathrm{NCS}$ and $\mathrm{H}_{2} \mathrm{C}=\mathrm{CH}-\mathrm{CH}_{2}-\mathrm{NCSe}$ molecules. 
The comparison between vinyl isocyanate and allyl isocyanate shows much weaker interaction between allyl $(0.85 \mathrm{eV})$ than vinyl $(2.85 \mathrm{eV})$ and $-\mathrm{NCO}$ functional group.

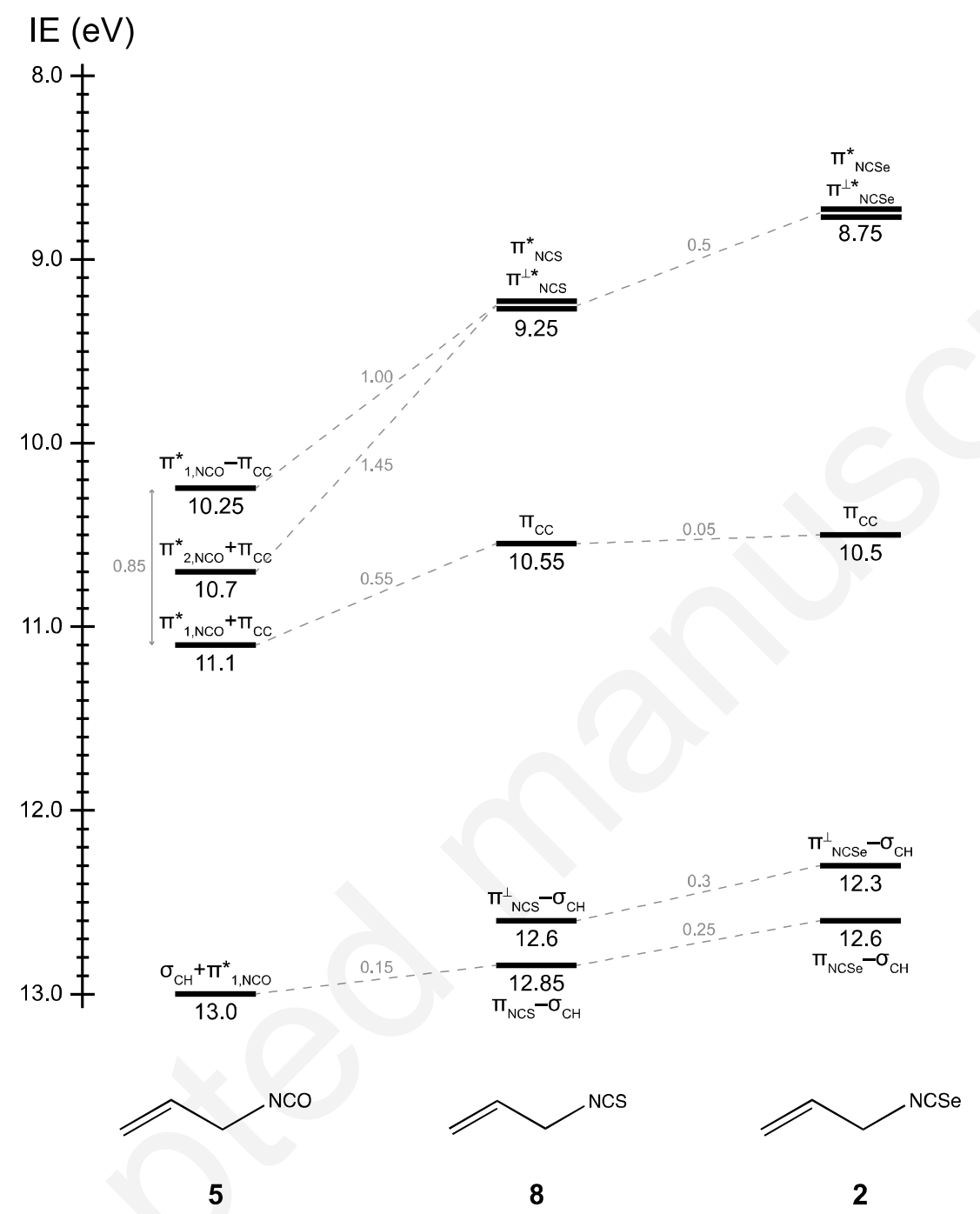

Figure 6. Comparison of the first four experimental ionization energies [eV] of allyl isocyanate $\mathbf{5}$, allyl isothiocyanate $\mathbf{8}$ and allyl isoselenocyanate $\mathbf{2}$.

To study cyclopropyl derivatives, a new compound, the cyclopropyl isoselenocyanate $\mathbf{3}$, has been synthesized. For cyclopropyl isothiocyanate $9,{ }^{54}$ it has been reported that the interaction of Walsh orbitals $\omega_{\mathrm{S}}$ and $\omega_{\mathrm{A}}$ of the cyclopropyl ring with the two out-of-plane combinations of $\pi_{2}$ of the isothiocyanato group (IE $=9.09 \mathrm{eV}: \pi_{2}(\mathrm{NCS})-\omega_{\mathrm{A}} ; \mathrm{IE}=9.45 \mathrm{eV}: \pi_{2}(\mathrm{NCS})-\omega_{\mathrm{S}}$ ) lowers the first and second IEs of the corresponding methyl isothiocyanate by 0.26 and 0.15 $\mathrm{eV}$, respectively. The UV-photoelectron spectra of cyclopropyl isoselenocyanate $\mathbf{3}$ and 
cyclopropyl isocyanate 6 are shown in Figure 7, and the corresponding IE calculations in comparison with experimental data are given in Tables S2 and S4. For the consistency of comparison, the known PE spectrum of cyclopropyl isothiocyanate $9^{54}$ and its interpretation are reported in Table S6. The low-energy band of cyclopropyl isoselenocyanate 3 at $8.45 \mathrm{eV}$ (a") arises from the ionization of the $\pi^{*}{ }_{\mathrm{NCSe}}$ orbital in antibonding interaction with the Walsh orbital $\omega_{\mathrm{A}}$, while the second band at $8.6 \mathrm{eV}$, (a') is assigned mainly to the $\pi^{\perp *}{ }_{\mathrm{NCSe}}$. The $\omega_{\mathrm{A}}$ $\pi_{\text {NCSe }}^{*}(\mathrm{a} ")$ and $\omega_{\mathrm{S}}-\pi^{\perp *}{ }_{\text {NCSe }}\left(\mathrm{a}^{\prime}\right) \mathrm{MO}$ 's ionizations appear at $10.95 \mathrm{eV}$ and $11.4 \mathrm{eV}$, respectively. The first IE of cyclopropyl isocyanate $6(9.9 \mathrm{eV}$, a") arises from the removal of an electron from the $\pi^{*}{ }_{\mathrm{NCO}}$ in antibonding interaction with the Walsh ${ }^{60}$ orbital $\omega_{\mathrm{A}}$, while the second IE $\left(10.75 \mathrm{eV}, \mathrm{a}^{\prime}\right)$ is assigned to the $\pi^{\perp *}{ }_{\mathrm{NCO}}$ in antibonding interaction with the Walsh orbital $\omega_{\mathrm{S}}$. The next two ionizations $\left(12.3 \mathrm{eV}, \mathrm{a} ; 12.7 \mathrm{eV}, \mathrm{a}\right.$ ") correspond to the $\omega_{\mathrm{S}}-\pi^{\perp *}{ }_{\mathrm{NCO}}$ and $\omega_{\mathrm{A}}-\pi_{\mathrm{NCO}}^{*}$, respectively. Higher energy ionizations are due to the $\sigma_{\mathrm{C}-\mathrm{H}}, \sigma_{\mathrm{C}-\mathrm{C}}$ and bonding combinations of $\pi$ NCO moiety with Walsh orbitals. As for cyclopropyl isoselenocyanate $\mathbf{3}$, higher energy ionizations are due to the $\sigma_{\mathrm{C}-\mathrm{H}}, \sigma_{\mathrm{C}-\mathrm{C}}$ and bonding combinations of $\pi$ NCO moiety with Walsh orbitals.

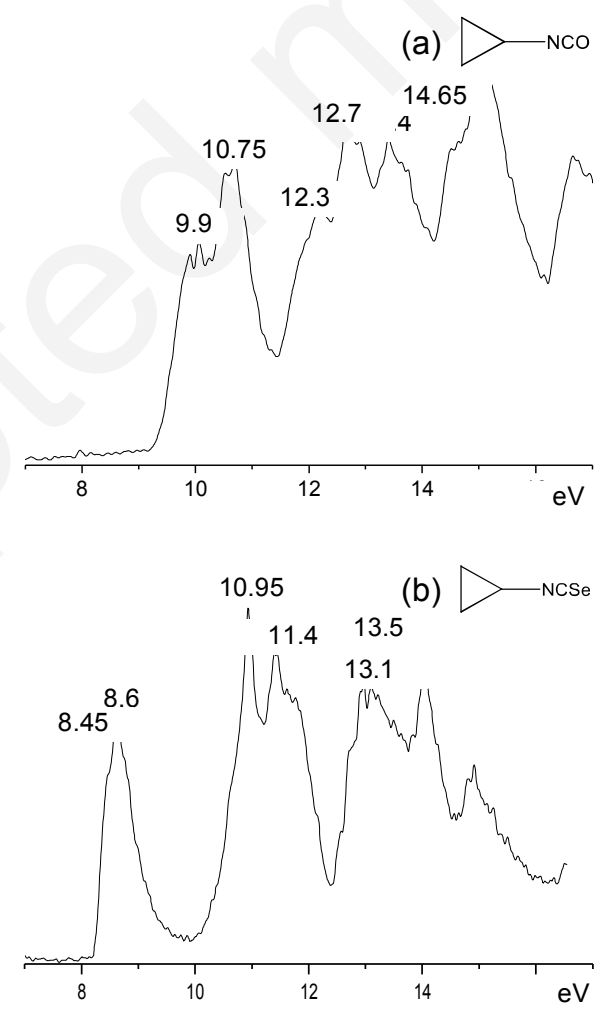

Figure 7. UV-Photoelectron spectra of (a) cyclopropyl isocyanate 6; (b) cyclopropyl isoselenocyanate 3 . 
Figure 8 summarizes the first four experimental ionization energies of cyclopropyl isocyanate 6, cyclopropyl isothiocyanate $\mathbf{9}^{54}$ and cyclopropyl isoselenocyanate $\mathbf{3}$.

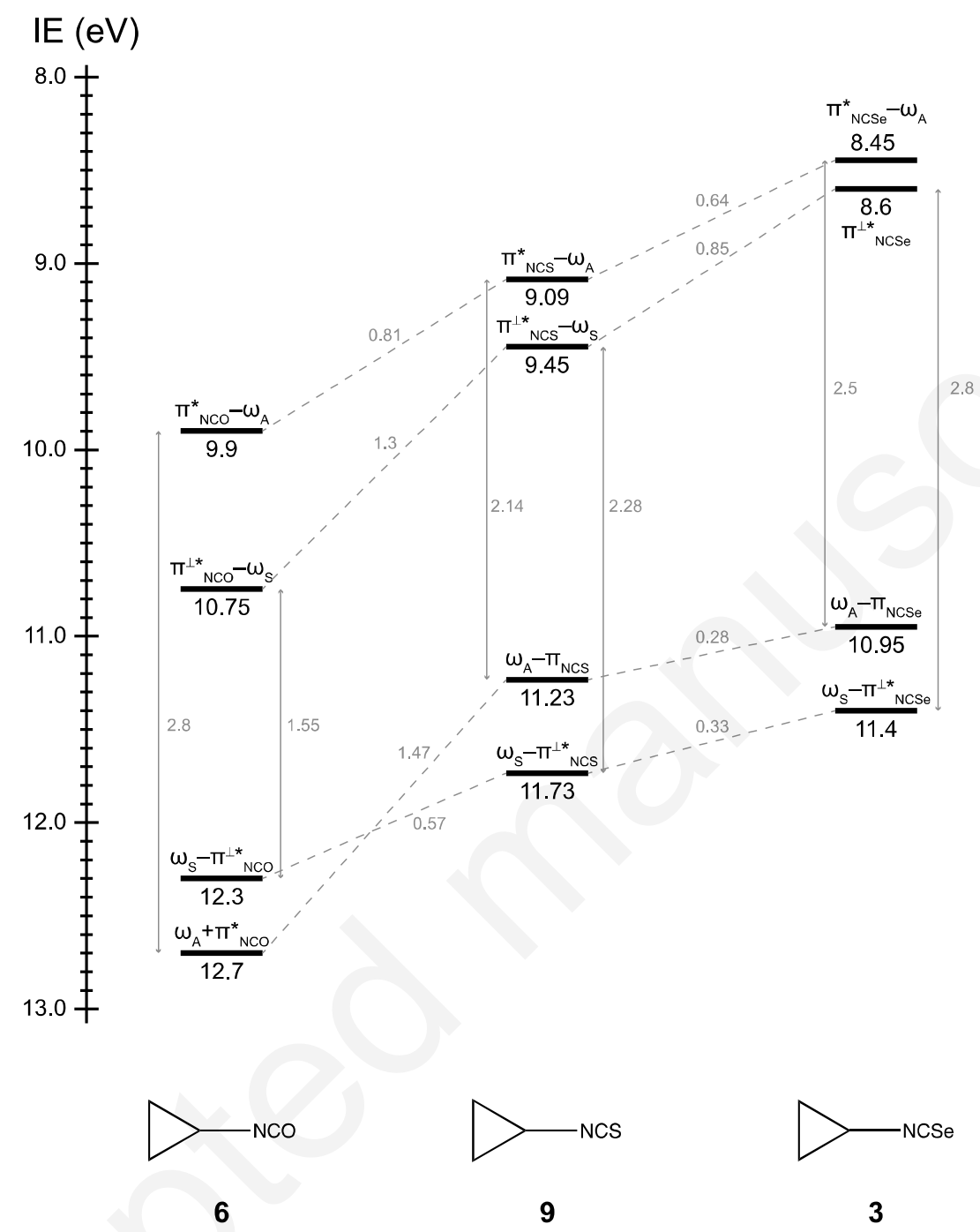

Figure 8. Comparison of first four experimental ionization energies $[\mathrm{eV}]$ of cyclopropyl isocyanate 6, cyclopropyl isothiocyanate $9^{54}$ and cyclopropyl isoselenocyanate 3 .

The comparison of the first four experimental ionization energies of cyclopropyl isocyanate 6, cyclopropyl isothiocyanate $9^{54}$ and cyclopropyl isoselenocyanate $\mathbf{3}$ shows a significant stabilizing (withdrawing) effect of oxygen atom since, as noted for vinyl and allyl derivatives, all IEs correspond to lower energy (higher IE values) than those of the sulfur or selenium -NCX functional group. The measure of the Walsh orbitals $\left(\omega_{\mathrm{A}}\right.$ and $\left.\omega_{\mathrm{S}}\right)$ interaction with -NCX moiety can be considered as an energy difference between $\pi^{*}{ }_{\mathrm{NCX}}-\omega_{\mathrm{A}}$ (or $\pi^{\perp *}{ }_{\mathrm{NCX}}{ }^{-}$ $\left.\omega_{\mathrm{S}}\right)$ and $\omega_{\mathrm{A}}-\pi_{\mathrm{NCX}}^{*}\left(\right.$ or $\left.\omega_{\mathrm{S}}-\pi^{\perp *}{ }_{\mathrm{NCX}}\right)$. The highest value of $2.8 \mathrm{eV}$ is obtained for $\pi^{*}{ }_{\mathrm{NCO}}-\omega_{\mathrm{A}} / \omega_{\mathrm{A}^{-}}$ 
$\pi^{*} \mathrm{NCO}$ of cyclopropyl isocyanate $\mathbf{6}$ and means that Walsh orbitals in this context have the same contribution as the vinyl substituent does $(2.85 \mathrm{eV})$. A slightly weaker input is conferred to the sulfur $(2.14 \mathrm{eV})$ and selenium derivatives $(2.5 \mathrm{eV})$.

Finally, the three photoelectron spectra of isoselenocyanates 1-3 can be compared to each other. As can be seen from the comparison of the first four experimental ionization energies of vinyl isoselenocyanate $\mathbf{1}$, allyl isoselenocyanate $\mathbf{2}$ and cyclopropyl isoselenocyanate $\mathbf{3}$ (Figure 9), the vinyl and cyclopropyl isoselenocyanates present similarities such as stronger interactions between the NCX functional group and the substituent (vinyl and cyclopropyl, respectively), while in the case of allyl and -NCSe functional groups two non-interacting moieties should be considered. 


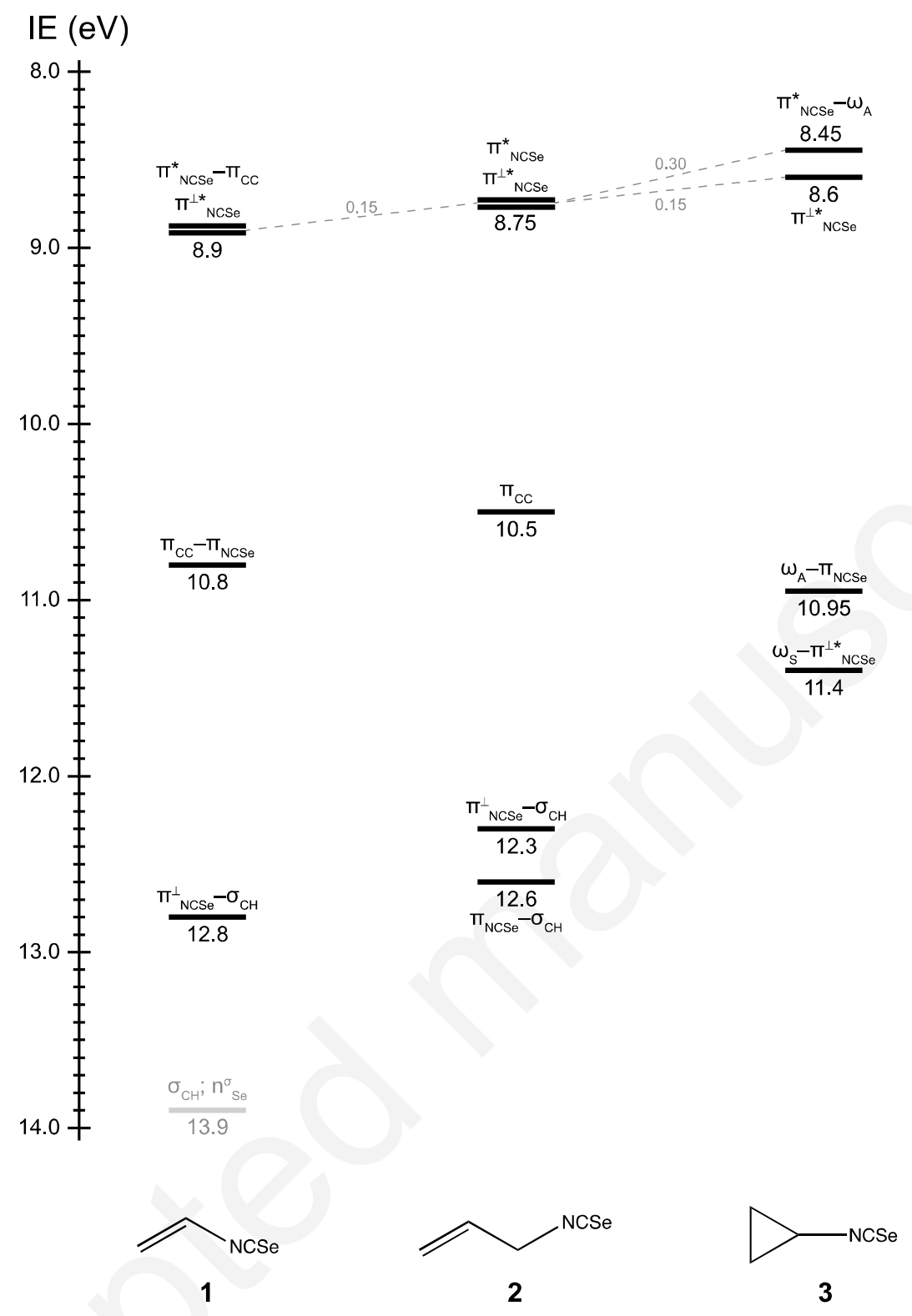

Figure 9. Comparison of first four experimental ionization energies $[\mathrm{eV}]$ of compounds 1-3.

\section{Conclusion}

For the vinyl series $\mathrm{H}_{2} \mathrm{C}=\mathrm{CH}-\mathrm{N}=\mathrm{C}=\mathrm{X}(\mathrm{X}=\mathrm{O}, \mathrm{S}$, Se), all IEs of selenium and sulfur derivatives are lowered in comparison with the corresponding isocyanate, showing a decrease of the strength of the vinyl substituent $\left(\pi_{C=C}\right)$ interaction with the $-N=C=X$ functional group. Similar effects were observed for cyclopropyl derivatives between the pseudo-unsaturated cyclopropyl substituent and the $\mathrm{N}=\mathrm{C}=\mathrm{X}$ moiety. Such an interaction between the functional groups in the allylic series was only observed for the oxygen derivative. The Figure 10 summarizes the comparisons between the first IE of these nine compounds. The influence of 
the vinyl, cyclopropyl and allyl substituents on the first IE of R-NCX $(X=\mathrm{Se}, \mathrm{O}, \mathrm{S})$ is clearly demonstrated. For $\mathrm{X}=\mathrm{Se}$, due to the weak interaction between the substituent and the $-\mathrm{NCSe}$ functional group, the higher lying HOMO is found for the cyclopropyl substituent. In the case of $\mathrm{X}=\mathrm{O}$, strongly interacting $-\mathrm{NCO}$ moiety and vinyl substituent, follow to the higher energy of HOMO in comparison with its cyclopropyl and allyl derivatives. The -NCS functional group is much less sensitive to a change of environment.

Thanks to the synthesis, theoretical calculations and photoelectron spectroscopy of the selenium derivatives, the type and extent of the interaction between the $\mathrm{N}=\mathrm{C}=\mathrm{X}(\mathrm{X}=\mathrm{O}, \mathrm{S}$, Se) group and an unsaturated (vinyl, allyl) or pseudo-unsaturated (cyclopropyl) moiety are now clarified as well as the comparison of the interactions with the substituent for each heteroatom.

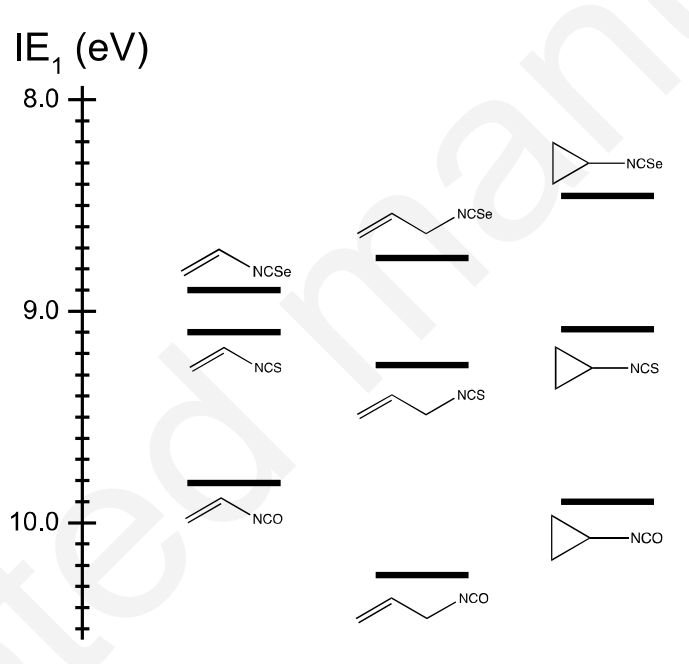

Figure 10. Comparison of first experimental ionization energies $[\mathrm{eV}]$ of compounds 1-9.

\section{Supporting Information.}

The SI part contains computational details (optimized geometries, energies, conformer studies) about compounds 1-9 and Tables (S1-S6) of comparison of calculated and experimental ionization energies $[\mathrm{eV}]$ for compounds $\mathbf{2}, \mathbf{3}, \mathbf{5}, \mathbf{6}, \mathbf{8}, \mathbf{9}$.

Acknowledgment. The authors thank P. Baylère for his efficient technical assistance. J.-C. G. thanks for funding the Centre National d'Etudes Spatiales (CNES) and the Programme 
National Physique et Chimie du Milieu Interstellaire (PCMI) of CNRS/INSU with INC/INP co-funded by CEA and CNES.

\section{References}

(1) Braverman, S.; Cherkinsky, M.; Birsa, M. L. Carbon Dioxide, Carbonyl Sulfide, Carbon Disulfide, Isocyanates, Isothiocyanates, Carbodiimides, and Their Selenium, Tellurium, and Phosphorus Analogues. Science of Synthesis. 2005, pp 65-320.

(2) Garud, D. R.; Koketsu, M.; Ishihara, H. Isoselenocyanates: A Powerful Tool for the Synthesis of Selenium-Containing Heterocycles. Molecules 2007, 12 (3), 504-535.

(3) López, Ó.; Maza, S.; Ulgar, V.; Maya, I.; Fernández-Bolaños, J. G. Synthesis of Sugar-Derived Isoselenocyanates, Selenoureas, and Selenazoles. Tetrahedron 2009, 65 (12), 2556-2566.

(4) Chennakrishnareddy, G.; Nagendra, G.; Hemantha, H. P.; Das, U.; Guru Row, T. N.; Sureshbabu, V. V. Isoselenocyanates Derived from Boc/Z-Amino Acids: Synthesis, Isolation, Characterization, and Application to the Efficient Synthesis of Unsymmetrical Selenoureas and Selenoureidopeptidomimetics. Tetrahedron 2010, 66 (34), 6718-6724.

(5) Ninomiya, M.; Garud, D. R.; Koketsu, M. Biologically Significant SeleniumContaining Heterocycles. Coord. Chem. Rev. 2011, 255 (23-24), 2968-2990.

(6) Franklin, W. J.; Werner, R. L. Alkyl Isoselenocyanates and Related Compounds. Tetrahedron Lett. 1965, 6 (34), 3003-3008.

(7) Tarantelli, T.; Leonesi, D. New Method for the Preparation of Organic Isoselenocyanates. Isomerization of Selenocyanates. Ann. Chim. 1963, 53, 1113-1122.

(8) Banert, K.; Toth, C. Synthesis and Reactions of Vinyl Isoselenocyanates. Angew. Chem. Int. Ed. Enol. 1995, 34 (15), 1627-1629.

(9) Møllendal, H.; Samdal, S.; Bunkan, A. J. C.; Guillemin, J.-C. Synthesis and Microwave Spectrum of Vinyl Isoselenocyanate $\left(\mathrm{H}_{2} \mathrm{C}=\mathrm{CHNCSe}\right)$, a Compound with a Quasilinear CNCSe Chain. J. Phvs. Chem. A 2012, 116 (16), 4074-4081.

(10) Chrostowska, A.; Matrane, A.; Maki, D.; Khayar, S.; Ushiki, H.; Graciaa, A.; Belachemi, L.; Guillemin, J.-C. Are Unsaturated Isocyanides so Different from the Corresponding Nitriles? ChemPhvsChem 2012, 13 (1), 226-236.

(11) Bajor, G.; Veszprémi, T.; Riague, E. H.; Guillemin, J.-C. Alkenyl Selenols and Selenocyanates: Synthesis, Spectroscopic Characterization by Photoelectron Spectroscopy, and Quantum Chemical Study. Chem. - Eur.J. 2004, 10 (15), 3649-3656.

(12) Guillemin, J.-C.; Bajor, G.; Riague, E. H.; Khater, B.; Veszprémi, T. Allenyl and Alkynyl Selenols and Selenocyanates. Synthesis, Spectroscopic Characterization, and Quantum Chemical Study. Organometallics 2007, 26 (10), 2507-2518.

(13) Khater, B.; Guillemin, J.-C.; Bajor, G.; Veszprémi, T. Functionalized Tellurols: Synthesis, Spectroscopic Characterization by Photoelectron Spectroscopy, and Quantum Chemical Study. Inorg. Chem. 2008, 47 (5), 1502-1511.

(14) Pasinszki, T.; Réffy, J.; Veszprémi, T. HeI Photoelectron Spectra of Alkyl Pseudohalides. J. Electron Spectrosc. Relat. Phenom. 1992, 58 (1-2), 159-165.

(15) Pasinszki, T.; Veszprémi, T.; Fehér, M.; Kovač, B.; Klasinc, L.; Mcglynn, S. P. The Photoelectron Spectra of Methyl Pseudohalides. Int. J. Ouantum Chem. 1992, 44 (S26), $443-$ 453.

(16) Veszprémi, T.; Pasinszki, T.; Fehér, M. Photoelectron Spectroscopic Studies of the Silicon Pseudohalides: Relationship between Geometrical and Electronic Structure. $\underline{\text { Chem }}$ Soc Earadav Trans 1991, 87 (24), 3805-3810.

(17) Dondoni, A.; Kniezo, L.; Medici, A. Selectivity in Cycloadditions to 
Vinylheterocumulenes. [2 + 2] and [4 + 2] Cycloaddition of (Diethylamino)Propyne to Vinyl Isocyanate and Vinyl Isothiocyanate. L. Org Chem. 1982, 47 (20), 3994-3998.

(18) Frisch, M. J.; Trucks, G. W.; Schlegel, H. B.; Scuseria, G. E.; Robb, M. A.; Cheeseman, J. R.; Scalmani, G.; Barone, V.; Mennucci, B.; Petersson, G. A.; et al. Gaussian09, Revision B.01; Gaussian, Inc.: Wallingford CT, 2009.

(19) Parr, R. G.; Yang, W. Density-Functional Theory of Atoms and Molecules. Oxford Univ. Press. Oxford 1989.

(20) Becke, A. D. Density-Functional Exchange-Energy Approximation with Correct Asymptotic Behavior. Phvs. Rev. A 1988, 38 (6), 3098-3100.

(21) Becke, A. D. Density Functional Thermochemistry. III. The Role of Exact Exchange. J. Chem. Phvs. 1993, 98 (7), 5648-5652.

(22) Lee, C.; Yang, W.; Parr, R. G. Development of the Colle-Salvetti Correlation-Energy Formula into a Functional of the Electron Density. Phvs. Rev. B 1988, 37 (2), 785-789.

(23) Yanai, T.; Tew, D. P.; Handy, N. C. A New Hybrid Exchange-correlation Functional Using the Coulomb-Attenuating Method (CAM-B3LYP). Chem. Phvs. Lett. 2004, 393 (1-3), $51-57$.

(24) Joantéguy, S.; Pfister-Guillouzo, G.; Chermette, H. Assessment of Density Functional Methods for the Calculation of Ionization Potentials of Unsaturated Molecules. J.Phvs. Chem. A 1999, 103 (18), 3505-3511.

(25) Chrostowska, A.; Miqueu, K.; Pfister-Guillouzo, G.; Briard, E.; Levillain, J.; Ripoll, J.-L. Gas-Phase Generation and Photoelectron Spectra of Reactive Unsubstituted Cycloalkenethiones. J. Mol. Spectrosc. 2001, 205 (2), 323-330.

(26) Bartnik, R.; Baylère, P.; Chrostowska, A.; Galindo, A.; Leśniak, S.; Pfister-Guillouzo, G. Flash Vacuum Thermolysis of 1-Azabicyclo[1.1.0]Butanes. Photoelectron Spectrum of 3Phenyl-2-Azabuta-1,3-Diene. Eur. J. Org. Chem. 2003, 2003 (13), 2475-2479.

(27) Runge, E.; Gross, E. K. U. Density-Functional Theory for Time-Dependent Systems. Phvs. Rev. Lett. 1984, 52 (12), 997-1000.

(28) Casida, M. E. Time-Dependent Density Functional Response Theory for Molecules. In Recent advances in densitv functional methods: Chong, D. P., Ed.; Wolrd Scientific: Singapore, 1995; pp 155-193.

(29) Lemierre, V.; Chrostowska, A.; Dargelos, A.; Chermette, H. Calculation of Ionization Potentials of Small Molecules: A Comparative Study of Different Methods. L Phvs. Chem.A 2005, 109 (37), 8348-8355.

(30) Mazière, A.; Chrostowska, A.; Darrigan, C.; Dargelos, A.; Graciaa, A.; Chermette, H. Electronic Structure of BN-Aromatics: Choice of Reliable Computational Tools. L.Chem. Phvs. 2017, 147 (16), 164306.

(31) Stratmann, R. E.; Scuseria, G. E.; Frisch, M. J. An Efficient Implementation of TimeDependent Density-Functional Theory for the Calculation of Excitation Energies of Large Molecules. J. Chem. Phvs. 1998, 109 (19), 8218-8224.

(32) Casida, M. E.; Jamorski, C.; Casida, K. C.; Salahub, D. R. Molecular Excitation Energies to High-Lying Bound States from Time-Dependent Density-Functional Response Theory: Characterization and Correction of the Time-Dependent Local Density Approximation Ionization Threshold. J. Chem. Phvs. 1998, 108 (11), 4439-4449.

(33) von Niessen, W.; Schirmer, J.; Cederbaum, L. S. Computational Methods for the OneParticle Green's Function. Comput. Phys. Rep. 1984, 1 (2), 57-125.

(34) Ortiz, J. V. Electron Binding Energies of Anionic Alkali Metal Atoms from Partial Fourth Order Electron Propagator Theory Calculations. J.Chem. Phvs. 1988, 89 (10), 6348.

(35) Nakatsuji, H.; Hirao, K. Cluster Expansion of the Wavefunction. Symmetry $\square$ adapted $\square$ cluster Expansion, Its Variational Determination, and Extension of Open $\square$ shell Orbital Theory. L.Chem. Phvs. 1978, 68 (5), 2053-2065.

(36) Nakatsuji, N. Cluster Expansion of the Wavefunction. Excited States. Chem. Phys. 
Lett. 1978, 59 (2), 362-364.

(37) Nakatsuji, H. Cluster Expansion of the Wavefunction. Calculation of Electron Correlations in Ground and Excited States by SAC and SAC CI Theories. Chem. Phvs. Lett. 1979, 67 (2-3), 334-342.

(38) Koopmans, T. Über Die Zuordnung von Wellenfunktionen Und Eigenwerten Zu Den Einzelnen Elektronen Eines Atoms. Phvsica 1934, 1 (1-6), 104-113.

(39) Foster, J. P.; Weinhold, F. Natural Hybrid Orbitals. J.Am. Chem. Soc. 1980, 102 (24), 7211-7218.

(40) Glendening, E. D.; Reed, A. E.; Carpenter, J. E.; Weinhold, F. NBO Version 3.1.

(41) Avogadro: An Open-Source Molecular Builder and Visualization Tool. Version 1.2.0. Http://Avogadro.Cc/.

(42) Hanwell, M. D.; Curtis, D. E.; Lonie, D. C.; Vandermeersch, T.; Zurek, E.; Hutchison, G. R. Avogadro: An Advanced Semantic Chemical Editor, Visualization, and Analysis Platform. J. Cheminformatics 2012, 4 (1), 17.

(43) Kolandaivel, P.; Jayakumar, N. Molecular Structure and Conformational Stability of Allylisocyanate-post-Hartree-Fock and Density Functional Theory Studies. J. Mol. Struct. THEOCHEM 2000, 530 (3), 311-320.

(44) Torgrimsen, T.; Klaboe, P.; Nicolaisen, F. Conformations and Vibrational Spectra of Allyl Isocyanate and Allyl Isothiocyanate. J. Mol. Struct. 1974, 20 (2), 213-227.

(45) Maiti, S.; Jaman, A. I.; Nandi, R. N. Microwave Spectrum of Allyl Isocyanate: Gauche Conformer. J. Mol. Spectrosc. 1993, 158 (1), 8-13.

(46) Maiti, S.; Jaman, A. I.; Nandi, R. N. Microwave Spectrum of Allyl Isothiocyanate: Gauche Conformer. J. Mol. Spectrosc. 1994, 165 (1), 168-172.

(47) Durig, J. R.; Berry, R. J.; Wurrey, C. J. Microwave, Infrared, and Raman Spectra, Conformational Stability, Structure, Dipole Moment, and Vibrational Assignment for Cyclopropyl Isocyanate. J. Am. Chem. Soc. 1988, 110 (3), 718-726.

(48) Heldmann, C.; Dreizler, H. Investigation of the Microwave Spectrum of Cyclopropyl Isocyanate. An Example for the Failure of Centrifugal Distortion Theory. Z Naturforsch 1990, $45 a, 1175-1184$.

(49) Durig, J. R.; Nease, A. B.; Berry, R. J.; Sullivan, J. F.; Li, Y. S.; Wurrey, C. J. Microwave Spectrum, Conformation, and Low Frequency Vibrational Spectrum of Cyclopropylisothiocyanate. L.Chem. Phvs. 1986, 84 (7), 3663-3671.

(50) Nguyen, M. T.; Hajnal, M. R.; Vanquickenborne, L. G.; Ha, T.-K.; Stohner, J. Structure and Conformation of Chlorosulfonylisocyanate and Cyclopropylisocyanate. $L$ Chem. Soc Earadav Trans. 1993, 89 (14), 2381-2384.

(51) Badawi, H. M.; Förner, W.; Seddigi, Z. S. MP2 C-N Barrier and Vibrational Spectra and Assignments for $\mathrm{CH} 2=\mathrm{CH}-\mathrm{N}=\mathrm{C}=\mathrm{X}(\mathrm{X}=\mathrm{O}, \mathrm{S}$ and $\mathrm{Se})$. L.Mol.Struct.THEOCHEM 2003, $631(1-3), 127-139$.

(52) Kirby, C.; Kroto, H. W. Microwave and Photoelectron Study of Cis- and TransIsocyanato Ethene, $\mathrm{CH} 2=\mathrm{CHNCO}$ (Vinyl Isocyanate). J. Mol. Spectrosc. 1978, 70 (2), 216228.

(53) Caminati, W. The Microwave Spectrum of S-Trans Vinyl Isothiocyanate. J. Mol. Struct. 1988, 190, 227-233.

(54) Rademacher, P.; Coskun, T.; Kowski, K.; Larionov, O.; de Meijere, A. Photoelectron Spectra and Electronic Structures of Some Acceptor-Substituted Cyclopropanes: Linear Correlation of Substituent Effects on MO Energies with Molecular Structures. Chem. Eur.J. 2003, 9 (13), 2953-2962.

(55) Pasinszki, T.; Yamakado, H.; Ohno, K. Penning Ionization of Thiocyanatomethane, Isocyanatomethane, and Isothiocyanatomethane by Collision with Helium*(23S) Metastable Atoms. J. Phvs. Chem. 1993, 97 (49), 12718-12724.

(56) Pasinszki, T.; Kishimoto, N.; Ohno, K. Penning Ionization Electron Spectroscopic and 
$\mathrm{Ab}$ Initio Study of the Interaction and Ionization of $\mathrm{HNCO}$ and $\mathrm{HNCS}$ with $\mathrm{He}^{*}\left(2^{3} \mathrm{~S}\right)$ Metastable and $\operatorname{Li}\left(2^{2}\right.$ S) Ground State Atoms. J.Phvs. Chem.A 1999, 103 (46), 9195-9203.

(57) Streets, D. G.; Berkowitz, J. Photoelectron Spectroscopy of Se2 and Te2. L_Electron Snectrosc. Relat.Phenom. 1976, 9 (3), 269-287.

(58) Potts, A. W.; Novak, I. Ultraviolet Photoelectron Spectra of Selenium and Tellurium. LElectron Spectrosc. Relat. Phenom. 1983, 28 (3), 267-277.

(59) Handbook of HeI Photoelectron Spectra of Fundamental Organic Molecules: Ionization Energies, Ab Initio Assignments, and Valence Electronic Structure for 200 Molecules; Kimura, K., Ed.; Japan Scientific Societies Press; Halsted Press: Tokyo: New York, 1981.

(60) Walsh, A. D. The Structures of Ethylene Oxide, Cyclopropane, and Related Molecules. Trans. Faradav Soc. 1949, 45, 179-190. 


\section{TOC Graphic}

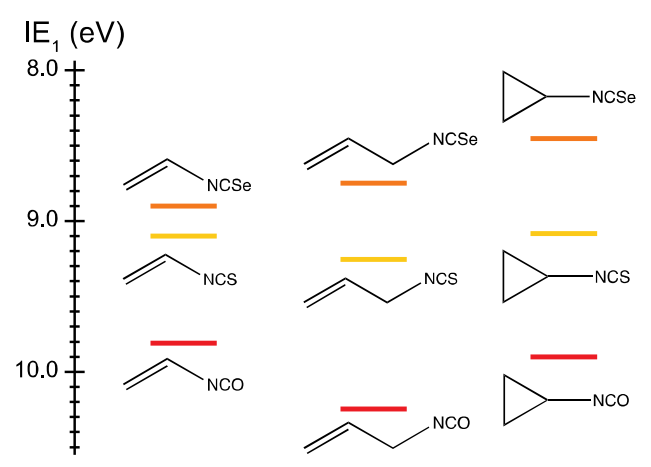



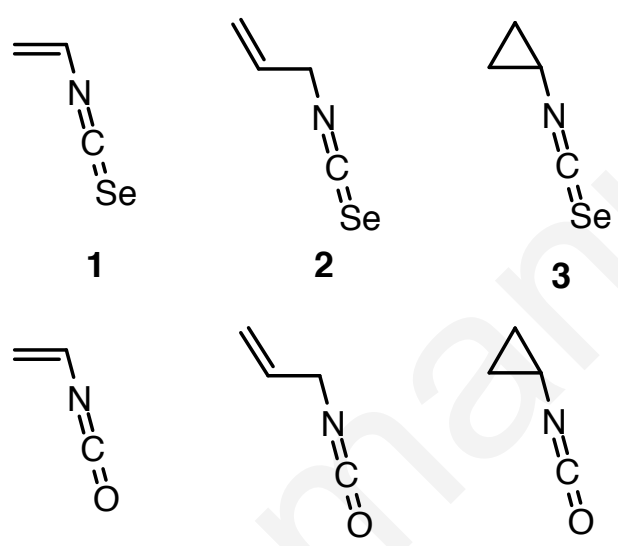

25

26
27

28

29

30

3

32

33

34

35

36

37

38

39

40

41

42

43

44

45

46

47

48

49

50

51

52

53

54

55

56

57

58

59

60

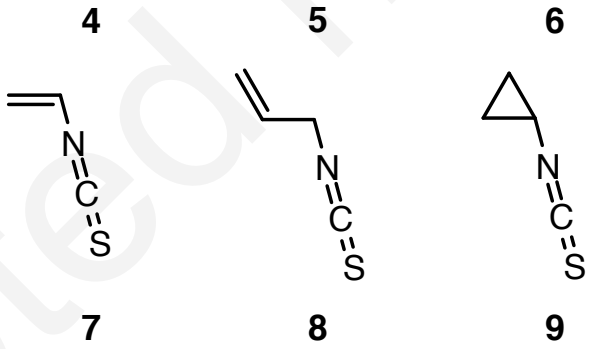




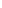




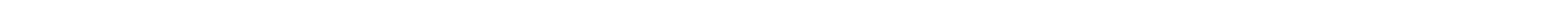




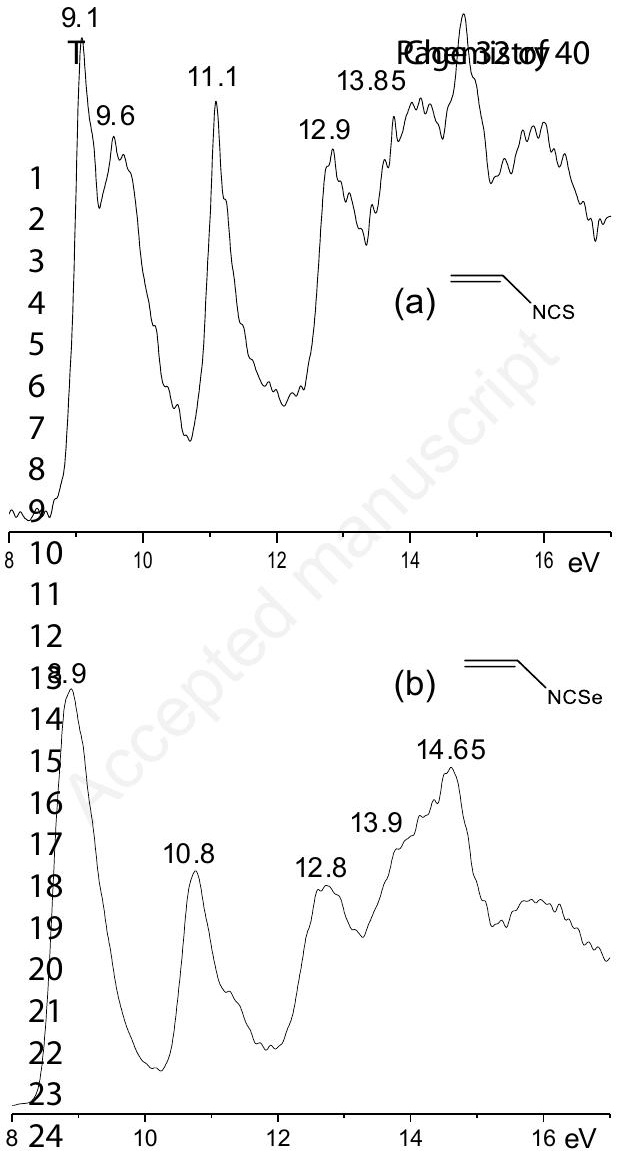




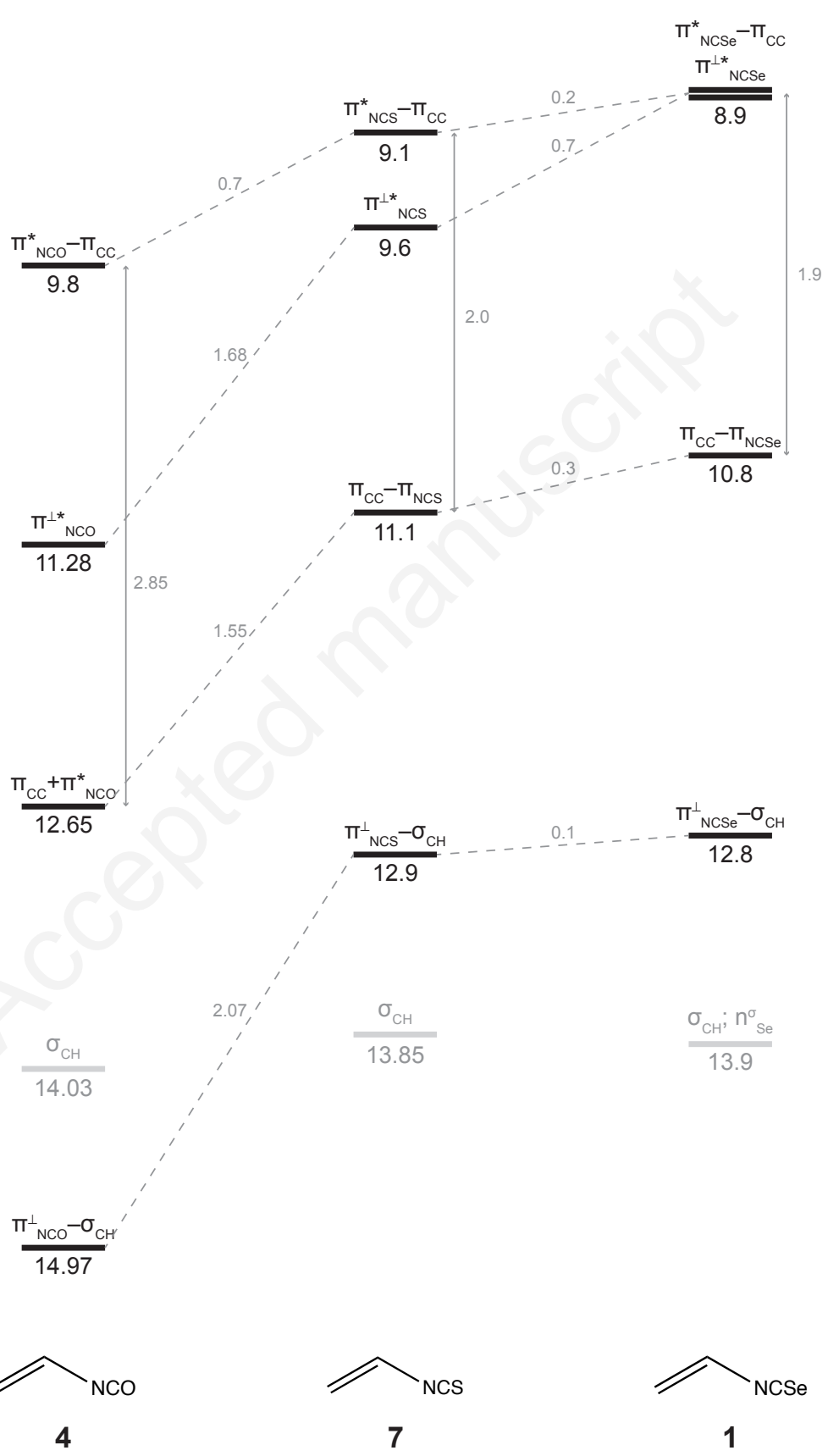

109

.

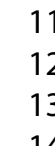
14
110 15
17
17

$18 f$ $19 f$ 120干 21 22 f 23

13 26 $27 f$ 28 $29 f$ $30 f$ 1439 32 33 34 35 1536 f

37

38

39

40

41 
10.7 


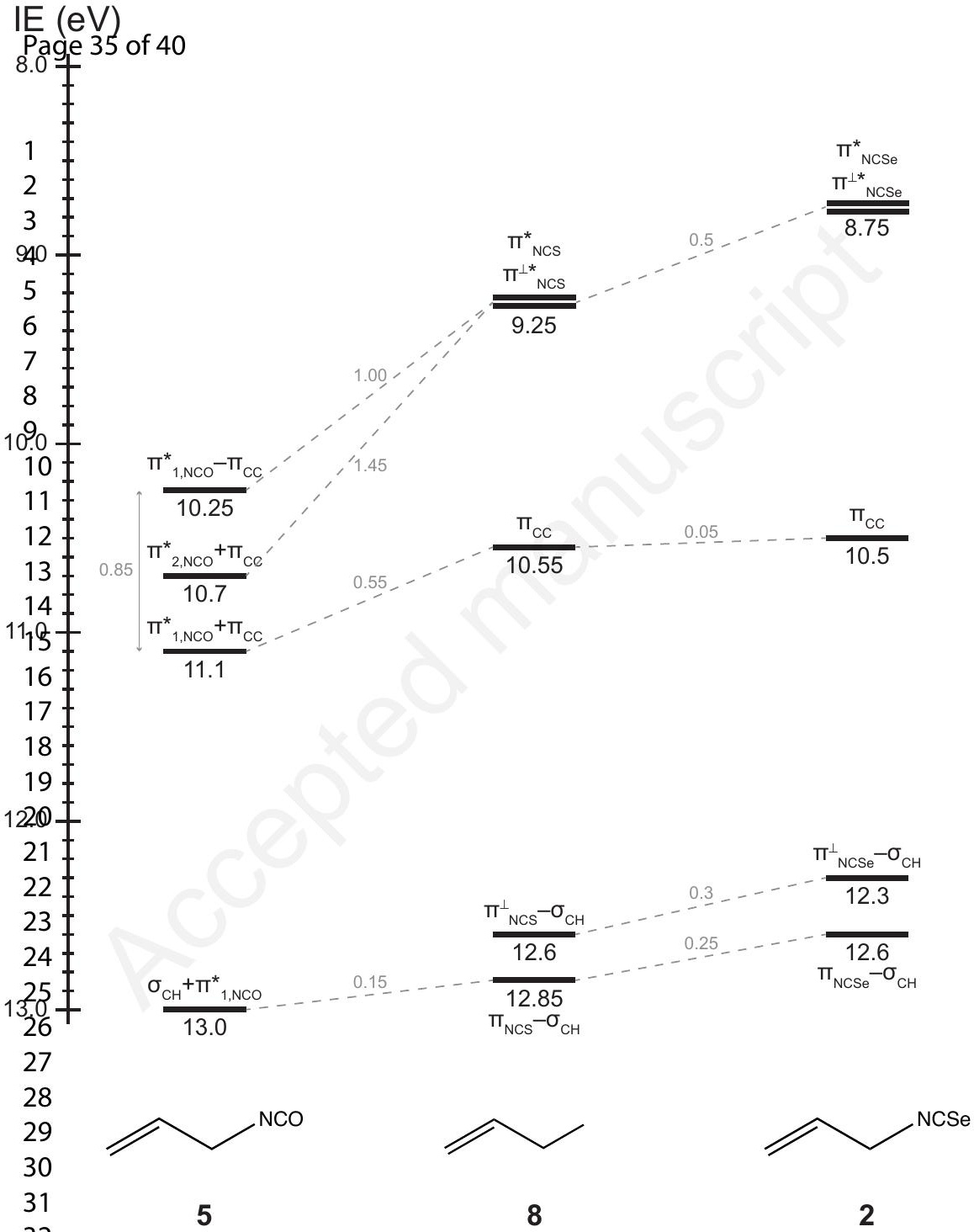



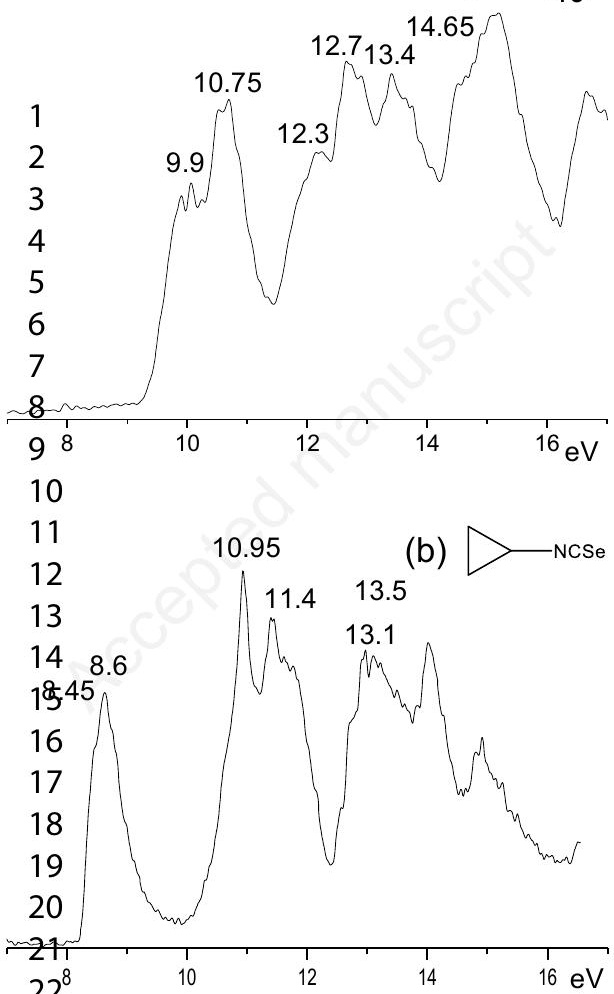


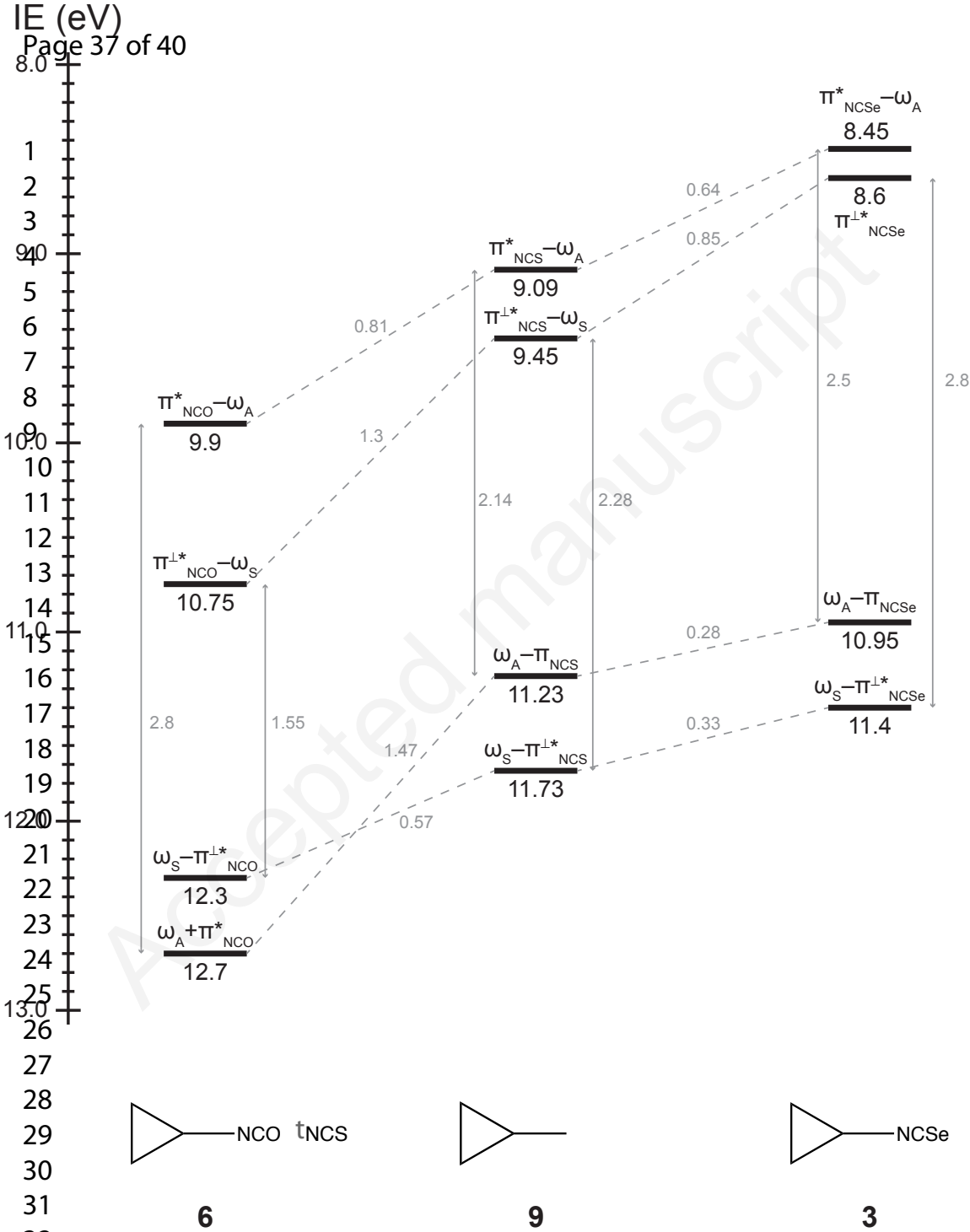




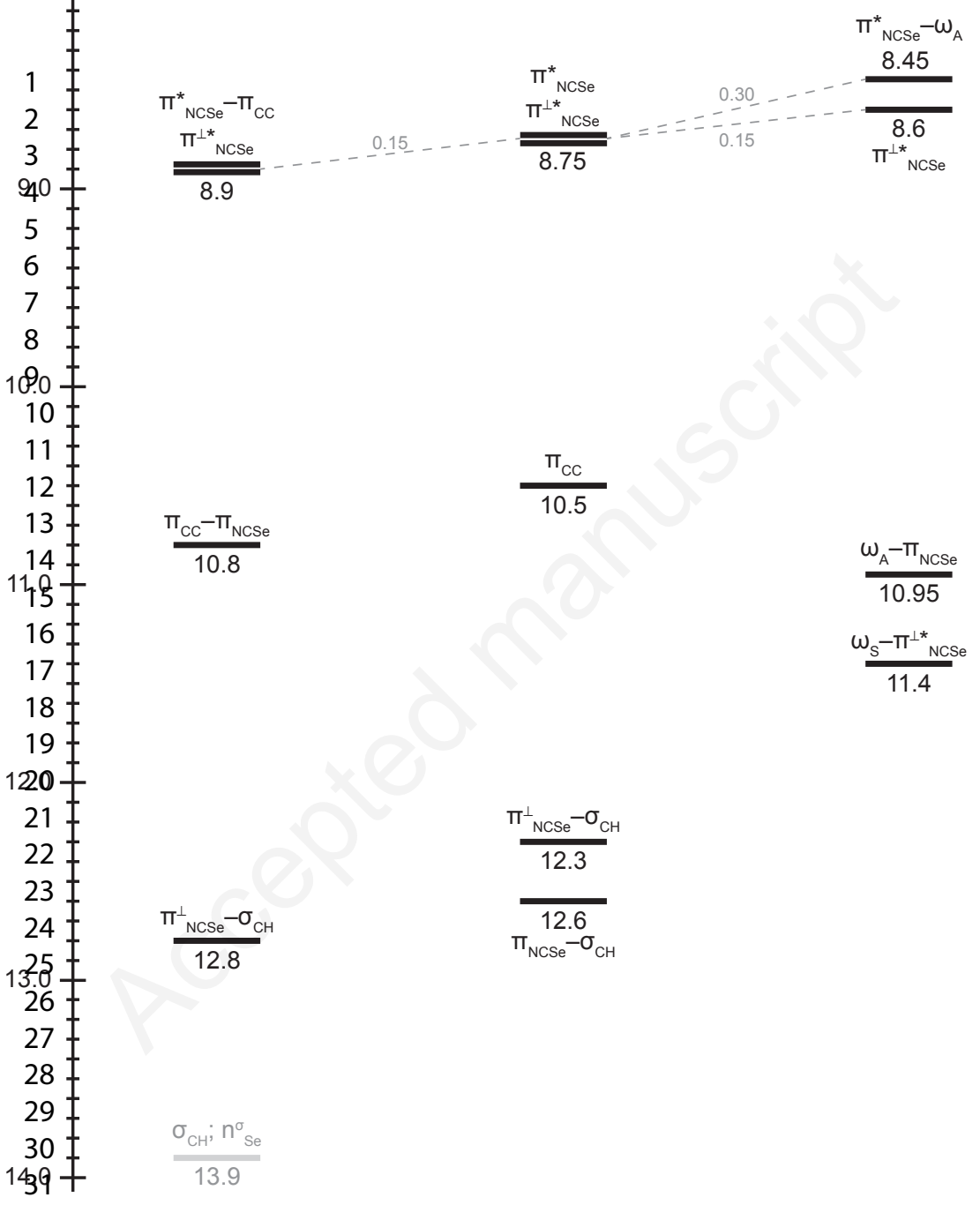

32

33

34

35

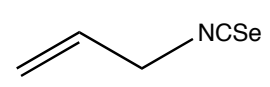

2

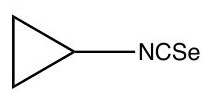

3 
$\mathrm{IE}_{1}(\mathrm{eV})$
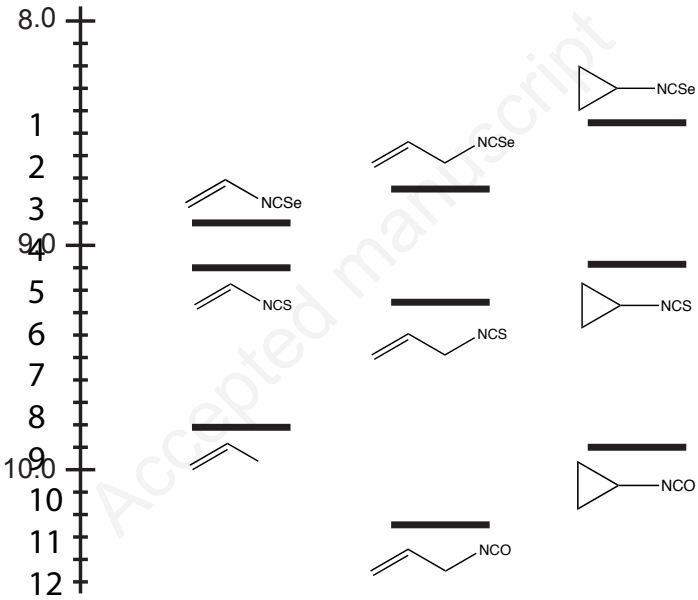
$\mathrm{IE}_{1}(\mathrm{eV})$
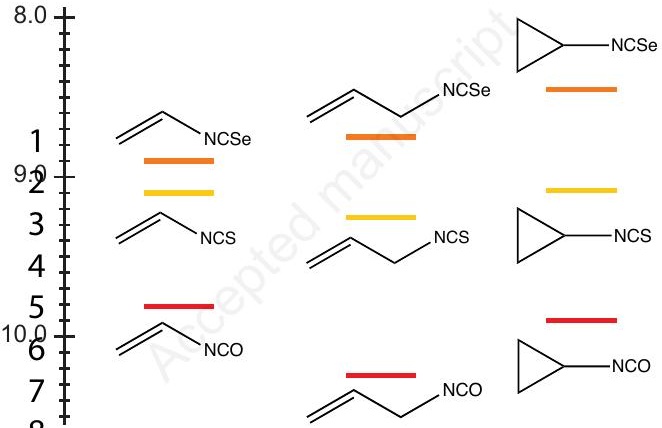